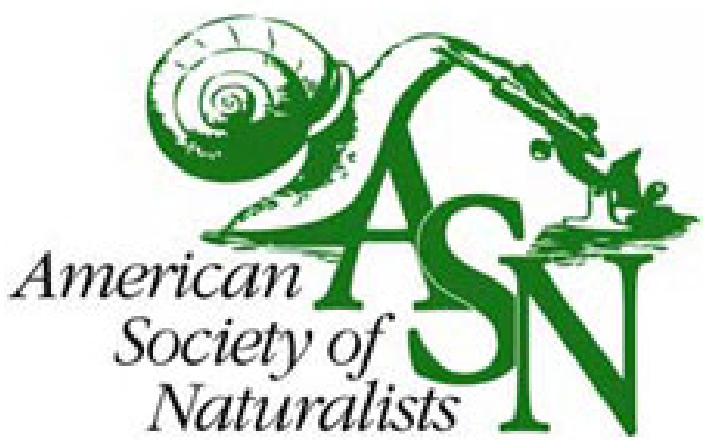

Persistence in Peripheral Refugia Promotes Phenotypic Divergence and Speciation in a Rainforest Frog.

Author(s): Conrad J. Hoskin, Maria Tonione, Megan Higgie, Jason B. MacKenzie, Stephen E. Williams, Jeremy VanDerWal, Craig Moritz

Reviewed work(s):

Source: The American Naturalist, Vol. 178, No. 5 (November 2011), pp. 561-578

Published by: The University of Chicago Press for The American Society of Naturalists

Stable URL: http://www.jstor.org/stable/10.1086/662164

Accessed: 29/01/2012 22:13

Your use of the JSTOR archive indicates your acceptance of the Terms \& Conditions of Use, available at http://www.jstor.org/page/info/about/policies/terms.jsp

JSTOR is a not-for-profit service that helps scholars, researchers, and students discover, use, and build upon a wide range of content in a trusted digital archive. We use information technology and tools to increase productivity and facilitate new forms of scholarship. For more information about JSTOR, please contact support@ jstor.org. 


\title{
Persistence in Peripheral Refugia Promotes Phenotypic Divergence and Speciation in a Rainforest Frog
}

\author{
Conrad J. Hoskin, ${ }^{1, \star, \dagger, \ddagger}$ Maria Tonione, ${ }^{2, \star}$ Megan Higgie, ${ }^{1, \ddagger}$ Jason B. MacKenzie, ${ }^{2, \S}$ \\ Stephen E. Williams, ${ }^{3}$ Jeremy VanDerWal, ${ }^{3}$ and Craig Moritz ${ }^{2}$
}

1. Division of Evolution, Ecology and Genetics, Research School of Biology, Australian National University, Canberra, Australian Capital Territory 0200, Australia; 2. Museum of Vertebrate Zoology, University of California, Berkeley, California 94720; 3. Centre for Tropical Biodiversity and Climate Change, School of Marine and Tropical Biology, James Cook University, Townsville, Queensland 4810, Australia

Submitted July 23, 2010; Accepted June 30, 2011; Electronically published October 10, 2011

Online enhancements: appendixes. Dryad data: http://dx.doi.org/10.5061/dryad.t215b.

\begin{abstract}
AвSTRACT: It is well established from the fossil record and phylogeographic analyses that late Quaternary climate fluctuations led to substantial changes in species' distribution, but whether and how these fluctuations resulted in phenotypic divergence and speciation is less clear. This question can be addressed through detailed analysis of traits relevant to ecology and mating within and among intraspecific lineages that persisted in separate refugia. In a biogeographic system (the Australian Wet Tropics [AWT]) with a well-established history of refugial isolation during Pleistocene glacial periods, we tested whether climate-mediated changes in distribution drove genetic and phenotypic divergence in the rainforest frog Cophixalus ornatus. We combined paleomodeling and multilocus genetics to demonstrate long-term persistence within, and isolation among, one central and two peripheral refugia. In contrast to other AWT vertebrates, the three major lineages differ in ecologically relevant morphology and in mating call, reflecting divergent selection and/or genetic drift in the peripheral isolates. Divergence in mating call and contact zone analyses suggest that the lineages now represent distinct species. The results show that climate shifts can promote genetic and phenotypic divergence and, potentially, speciation and direct attention toward incorporating adaptive traits into phylogeographic studies to better resolve the mechanisms of speciation.
\end{abstract}

Keywords: morphology, mating traits, Pleistocene refugia, contact zone, Wet Tropics, Cophixalus.

\section{Introduction}

The current geographic ranges of species are largely determined by climate as a consequence of physiological tol-

\footnotetext{
* These authors contributed equally to this article.

† Corresponding author; e-mail: conrad.hoskin@jcu.edu.au.

${ }^{\ddagger}$ Present address: School of Marine and Tropical Biology, James Cook University, Townsville, Queensland 4811, Australia.

$\S$ Present address: The Nature Conservancy, San Francisco, California 94105.

Am. Nat. 2011. Vol. 178, pp. 561-578. () 2011 by The University of Chicago. 0003-0147/2011/17805-52326\$15.00. All rights reserved. DOI: $10.1086 / 662164$
}

erances and habitat requirements (Grinnell 1917; Williams et al. 2007), though physical barriers and biotic interactions can also constrain distributions at local or regional scales (Soberon and Nakamura 2009). Climate change is expected to alter distributions as suitable ecological conditions for a species shift across the landscape. That this is the case is evident from fluctuation in species ranges in association with late Quaternary or more recent climate change (Jackson and Overpeck 2000; Parmesan 2006; Tingley et al. 2009), which often results in novel assemblages due to idiosyncratic responses of species (Graham et al. 1996; Williams et al. 2007; Moritz et al. 2008). Although climatic fluctuations have occurred throughout Earth's history, particular attention has been paid to the role in shaping current diversity of the well-characterized global climatic fluctuations associated with the Pleistocene glacial cycles (e.g., Haffer 1969; Moritz et al. 2000; Hewitt 2004; Zink et al. 2004; Turgeon et al. 2005).

The net effects of past climate change on a speciesrange expansion, contraction, fragmentation, or consolidation-depend on how the geography of ecological conditions change across the landscape. The ensuing demographic effects should be evident in spatial patterns of current genetic diversity. Expectations include high genetic diversity in presumed refugial areas or areas of current admixture among historically isolated lineages and reduced diversity and signatures of population expansion in recently recolonized regions (Petit et al. 2003; Hewitt 2004). Accordingly, many phylogeographic studies reveal clear signatures of these past events (Hewitt 2004). More recently, such studies have been extended to include multiple loci and/or codistributed taxa and to employ increasingly sophisticated analytical methods that use coalescent simulations to test alternative hypotheses or infer parameters relating to historical demography (Turgeon et al. 2005; Knowles 2009; Hickerson et al. 2010). The field has also 
advanced by using spatial modeling of potential ranges under past climates to predict geographic regions of potential persistence ("refugia") versus instability (i.e., alternating extinction and recolonization) that can then be tested via statistical phylogeographic analysis (Hugall et al. 2002; Richards et al. 2007; Carnaval et al. 2009; Walker et al. 2009).

Less clear is how these repeated, climate-driven fluctuations in geographic range and ecological conditions translated into phenotypic divergence, and perhaps speciation, among isolates. In principle, geographic responses to climatic oscillations could alter connectivity among populations, the potential for genetic drift, and selection regimes across populations. Retraction of populations during climatically restrictive periods (e.g., at glacial maxima) could result in the following: (1) extirpation of all but one persistent lineage, which subsequently expands its range; (2) persistence of lineages in ecologically similar but isolated refugia (Haffer 1969); or (3) persistence in ecologically distinct, disjunct refugia. If the first scenario applies, we would expect genetic and phenotypic similarity over the entire range. The second scenario would also be expected to result in little phenotypic divergence. Across environmentally similar refugia, the combined effect of drift on neutral genes (Lynch 1990; Coyne and Orr 2004) and stabilizing or uniform directional selection on phenotypes (Charlesworth et al. 1982; Wiens and Graham 2005; Nosil and Flaxman 2011) is expected to produce genetically divergent but phenotypically similar lineages, that is, "cryptic" lineages (Bickford et al. 2006; Kozak et al. 2006; Bond and Stockman 2008). In contrast, in the third scenario we would expect concordant phylogeographic and phenotypic divergence among historical isolates. Differences in biotic or abiotic environment across refugia would potentially result in a heterogeneous selection regime among allopatric populations, resulting in local adaptation and potentially rapid speciation (McPeek 1996; Schluter 2001; Gavrilets 2004; McPeek and Gavrilets 2006; Hoskin and Higgie 2010). Phenotypic divergence would be expected in ecologically relevant morphology (Endler 1986; Schluter 2001; Losos 2009) and mating traits (Gerhardt and Huber 2002; Hoskin and Higgie 2010).

Rigorous phenotypic analysis integrated with thorough analyses of population history offers an approach to testing the mechanistic role of past climate shifts in diversification. Here we combine paleomodeling, genetics, and phenotypic data (ecologically relevant morphology and mating call) to assess how past climate change has shaped present genetic and phenotypic diversity across the range of a rainforest frog species. We use niche modeling to predict areas of persistence in the past, particularly at the last glacial maximum (LGM). If the range of the species was fragmented to isolated refugia in the past, and if selection pressures differed among those refugia, then we predict the following: (1) spatial correspondence between major lineages and areas of predicted persistence; (2) higher genetic diversity in regions of predicted paleorefugia, particularly where these are predicted to have been larger, and intervening areas containing a subset of the diversity contained in refugia; (3) genetic signatures of range expansion, particularly for lineages that are predicted to have contracted historically to small refugia; and (4) divergence in ecologically important phenotypic traits due to differing selection pressures among refugia. Finally, if genetic and phenotypic (particularly mating trait) divergence is substantial, reproductive isolation should be evident where the lineages are currently in contact.

\section{The Study System}

The Australian Wet Tropics (hereafter, AWT) underwent repeated fluctuations in area and connectivity during the Pleistocene, with the most severe contractions occurring at the LGM $(\sim 18$ thousand years ago [kya]; Hopkins et al. 1993; Kershaw et al. 2005). During glacial periods, cooldry conditions forced the contraction of rainforests to small, mostly montane refugia, primarily in the central and northern AWT (Webb and Tracey 1981; Nix 1991; VanDerWal et al. 2009). Under current climatic conditions, rainforest distribution is fairly continuous throughout the AWT. Genetic studies of currently widespread rainforest species have consistently revealed deep phylogeographic structure, reflecting historic isolation of populations to refugia for extended periods (Joseph et al. 1995; Schneider et al. 1998; Moussalli et al. 2009; Bell et al. 2010). However, the spatial and temporal scales of species' responses vary; some show a relatively simple pattern of north/south lineages (Joseph et al. 1995; Schneider et al. 1998; Hoskin et al. 2005), whereas others (particularly invertebrates) have multiple, localized lineages, suggesting persistence in multiple small refugia (e.g., Hugall et al. 2002; Bell et al. 2007). Despite extended periods of isolation, little phenotypic divergence has been detected between phylogeographic lineages of AWT vertebrates (Schneider and Moritz 1999; Hoskin 2007; Moritz et al. 2009), but few have been assessed in detail (for exceptions, see Hoskin et al. 2005; Bell et al. 2010).

Cophixalus are small, terrestrial-breeding microhylid frogs, generally restricted to rainforest, that have low dispersal capabilities (Zweifel 1985; Hoskin 2004; Williams et al. 2010). Cophixalus represents the only diverse vertebrate radiation within the AWT, and the genus shows patterns of diversity and endemism that are more akin to those of the low-dispersal invertebrate groups of this region. Of the 14 Australian species, 11 form a monophyletic group that is endemic to the AWT, with most species being localized to one or a few neighboring mountaintops (Hos- 
kin 2004). The species are morphologically similar but differ in traits deemed to be of ecological relevance, particularly body size and the size of the finger pads (Zweifel 1985; Hoskin 2004). Biogeographic and phylogenetic analyses suggest a Miocene/Pliocene in situ radiation (Hoskin 2004), with high persistence compared with that of other vertebrates through the Pleistocene climatic oscillations (Graham et al. 2006). In contrast to its congeners, the ornate nursery frog Cophixalus ornatus is widespread in the AWT, occurring widely in middle- and high-altitude rainforest (400-1,600 $\mathrm{m}$ above sea level) and some wet lowland areas (fig. 1). As with most frogs (Gerhardt and Huber 2002), the primary means of mate choice in $C$. ornatus is male mating call (Hoskin 2004; Felton et al. 2006). Cophixalus ornatus is a "generalist" rainforest species when compared with most other AWT rainforest vertebrates, as calculated through rainforest and ecological niche specialization scores (Williams et al. 2010). It occurs in all rainforest types within its range and extends into associated areas of sclerophyll forest and montane heath.

We chose C. ornatus, a small, low-vagility, terrestrialbreeding, generalist rainforest frog, for a study of the effects of climate shifts on genetic and phenotypic divergence for the following reasons. Small body size enhances persistence in small habitat areas, and low vagility increases the potential for isolation and subsequent divergence (Coope 2004; Turgeon et al. 2005). This is supported by the fact that lowvagility invertebrates (e.g., flightless beetles, snails, spiders) typically show fine-scale patterns of phylogeographic structuring (Hugall et al. 2002; Bell et al. 2007; Boyer et al. 2007; Starrett and Hedin 2007; Bond and Stockman 2008; Walker et al. 2009). Breeding mode is important because small montane refugial areas are more likely to have retained suitable conditions for some breeding modes (e.g., terrestrial breeding in moist leaf litter) than others (e.g., stream or pool breeders). Indeed, small-bodied, terrestrial-breeding rainforest frogs show patterns of higher persistence than aquatic breeders in the AWT (Graham et al. 2006). Regarding habitat specialization, it may be argued that specialized species are likely to be more severely isolated by habitat fragmentation (and so may be expected to show greater structuring; Knowles 2000; Turgeon et al. 2005), but these species are also more likely to become extinct when refugia become small or ecologically marginal to core habitat conditions. The relative persistence of more generalist species may therefore be reflected in more complex phylogeographic structuring. Generalist species are also more likely to persist in refugia that differ environmentally and thereby provide greater opportunity for divergent selection and consequent phenotypic change. Finally, frogs are ideal because the functionality of morphological traits is generally well known (Wells 2007) and male mating call has been well

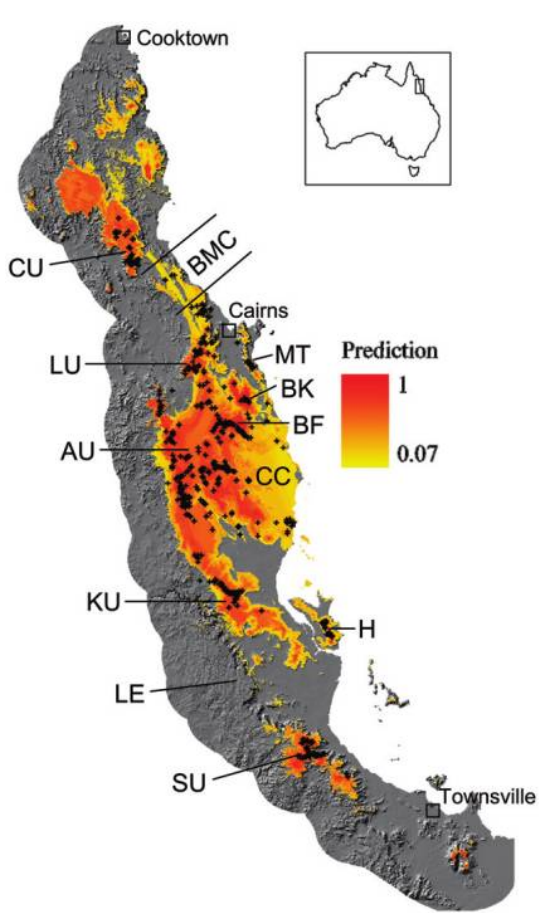

Figure 1: Distribution of Cophixalus ornatus in the Australian Wet Tropics as defined by 941 distribution records (black dots) and as predicted by the Maxent distribution model (yellow-to-red scale). Localities referred to in the text are marked as follows: AU, Atherton Tableland uplands; BF, Mount Bartle Frere; BK, Mount Bellenden Ker; BMC, Black Mountain Corridor; CC, Cairns-Cardwell lowlands; CU, Carbine Tableland uplands; H, Hinchinbrook Island; KU, Kirrama Range uplands; LE, Mount Lee uplands; LU, Lamb Range uplands; MT, Malbon Thompson Range; SU, Mount Spec uplands.

established to be the key mating trait (Gerhardt and Huber 2002).

\section{Methods}

\section{Field Sampling}

Sampling across the geographical range of $C$. ornatus was extensive, enabling a thorough assessment of phylogeographic and phenotypic diversity. A total of 788 individuals were sampled from 55 sites, averaging 14.3 individuals per site (app. A, available online). Intensive sampling was conducted in the regions of highest genetic diversity (on the basis of preliminary analysis), including an approximate north-south transect to the west of Mount Bartle Frere and an approximate east-west transect from the coastal lowlands over Mount Bartle Frere (fig. C1, available online). Cophixalus ornatus occurs at high density over much of its distribution; however, it is generally detected only when males call in the summer wet season. Sampling tar- 
geted calling males $(N=739 ; 93.8 \%$ of all samples), which provided a large data set of sexually mature individuals of one sex for phenotypic analyses. All frogs were measured and tissue was sampled, and then frogs were released at the point of capture. For genetic analysis, a very small $(<2 \mathrm{~mm})$ terminal portion of the second toe of the right foot was removed and placed in $95 \%$ ethanol. All genetic samples and a small number of voucher specimens are currently housed at the Australian National University (C.J.H.). All collections will ultimately be deposited in the Queensland Museum. Calls were recorded from selected sites. GPS position and altitude $( \pm 5 \mathrm{~m})$ were recorded at each site. All morphology and call data were obtained by one of us (C.J.H.). Frogs were measured using vernier calipers (to the nearest $0.1 \mathrm{~mm}$ ) and a $5-\mathrm{g}$ springloaded Pesola (to the nearest $0.05 \mathrm{~g}$ ). Morphology and call data sets are deposited at Dryad (http://dx.doi.org/ 10.5061/dryad.t215b).

Morphological traits encapsulating body size and shape are widely used to assess divergent selection across environments (Endler 1986; Smith et al. 1997; Schluter 2001; Hoskin et al. 2005; Losos 2009; Collar et al. 2010). We measured the following widely used frog morphology measurements (Hoskin et al. 2005; Wells 2007): snout-vent length (SVL), tarsus length (TL), head width (HW), width of the disk on the third (i.e., longest) finger (DISK), and weight (WT). Although the functionality of these traits has not been specifically established for this species, they are deemed of likely ecological relevance on the basis of patterns of variation across ecologically different Cophixalus species (C. J. Hoskin, unpublished data) and studies of other organisms (e.g., Hoskin et al. 2005; Losos 2009; Collar et al. 2010). These traits likely reflect the way a frog functions in its environment in terms of, for example, jumping and climbing abilities (size, TL, DISK), substrate use (size, DISK), and prey size selection (size, HW). Here we did not place particular relevance on variation in individual morphological traits but rather treated size and shape variation as multivariate indicators of ecological divergence.

Traits used by animals in the process of choosing their mates (mating traits), where these can be confidently identified (e.g., frog call), also offer potential insights into divergent selection across different biotic or abiotic environments (Ryan and Wilczynski 1991; McPeek 1996; Gerhardt and Huber 2002; Kirshel et al. 2009; Hoskin and Higgie 2010; Tobias et al. 2010) as well as insights into the degree of reproductive isolation between populations (Gerhardt and Huber 2002; Coyne and Orr 2004; Hoskin et al. 2005). As it is for most frogs (Gerhardt and Huber 2002; Wells 2007), mating call is the primary means of mate choice in C. ornatus (Hoskin 2004; Felton et al. 2006). Male mating calls were recorded in the field using a Sony
Professional DAT recorder (TCD-D100) and a Sennheiser (K6 ME-66) directional microphone. Recording did not commence until the male had uttered an uninterrupted string of 10 calls. Following this, approximately 10 consecutive calls were recorded. Air temperature was recorded to the nearest $0.1^{\circ} \mathrm{C}$ and the male was measured, tissue sampled, and then released at the point of capture. Calls were sampled at $44,100 \mathrm{~Hz}$ on a Macintosh G4, and the software Canary, version 1.2.1, was used to measure traits. Four calls were randomly chosen for each male to give the average call characteristics of that individual. The following standard frog call traits (Gerhardt and Huber 2002; Hoskin 2004; Hoskin et al. 2005; Felton et al. 2006) were measured: dominant frequency (DF), the frequency at which the call is of greatest intensity; call duration (DUR), measured from the first pulse peak of the call to the last pulse peak of the call; and pulse rate (PULSE), in pulses per second.

\section{Modeling of Potential Distributions under Current and Past Climates}

The maximum entropy (Maxent, ver. 3.2.1) method (Phillips et al. 2006) was applied to 941 distribution records for C. ornatus (fig. 1), using the general approach described by VanDerWal et al. (2009). The 941 records came primarily from field surveys by S.E.W. and C.J.H. and from Queensland Museum specimen data, and all are highly reliable and carefully vetted (Williams et al. 2010). The distribution records are deposited at Dryad (http://dx.doi.org/10.5061/ dryad.t215b). Background points $(\sim 36,000)$ were extracted from a 1-km grid of the AWT bioregion. Seven biologically meaningful climate variables were obtained for the region from an 80-m-resolution climate surface: annual mean temperature, annual mean precipitation, minimum temperature of the coldest quarter, precipitation of the driest and wettest quarters, and temperature of the wettest and coldest quarters. Following Hilbert et al. (2007), we applied the following climate shifts (as originally estimated from local palynological records; Kershaw and Nix 1988) to three periods representative of different phases of Pleistocene climate cycles: the cool-dry LGM (18 kya), the cool-wet PleistoceneHolocene transition (PHT; 10-8 kya), and the warm-wet Holocene Climatic Optimum (HCO; 5-3.5 kya). These three time periods are considered to best reflect major changes in rainforest distribution in the AWT through the Quaternary (Kershaw and Nix 1988; Graham et al. 2006; Hilbert et al. 2007; VanDerWal et al. 2009). The temperature variables were adjusted relative to the present climate by $-3.5^{\circ},-2^{\circ}$, and $+2^{\circ} \mathrm{C}$ for the LGM, PHT, and HCO, respectively. For precipitation variables, multipliers of current conditions of $0.5,2$, and 1.25 were applied for the LGM, PHT, and HCO, respectively. The exception was for pre- 
cipitation of the driest quarter, where the multiplier for HCO was 1.5. The paleomodeling did not account for changes in sea level because paleoecological data (Kershaw et al. 2005) and previous climatic modeling (Moussalli et al. 2009) have indicated that rainforest was not extensive on the continental shelf.

\section{Genetic Data and Analysis}

Genetic Data Collection. Total genomic DNA was extracted from toe pads, using a method similar to that outlined by Aljanabi and Martinez (1997). Using polymerase chain reaction (PCR), we amplified and sequenced one mitochondrial fragment and four nuclear fragments. The mitochondrial fragment was a section of the $16 \mathrm{~S}$ ribosomal RNA gene (16S rDNA). Due to coamplification of a nuclear pseudogene of $16 \mathrm{~S} \mathrm{rDNA}$, we designed primers specific for C. ornatus $16 \mathrm{~S}$. We also designed primers specific to the $16 \mathrm{~S}$ pseudogene and used it as a nuclear locus for analysis. To obtain additional nuclear loci, we sequenced the flanking regions for three previously described microsatellite markers (Bardeleben et al. 2006) from geographically diverse $C$. ornatus, using new primer sets we designed. For details of all primers and PCR and sequencing protocols, see appendix C, available online. Sequences are deposited in GenBank (accession numbers: for 16S, JF743691-JF743761; for 16S pseudogene, JN034917JN035138; for Corn304, JN012244-JN012465) and Dryad (for Corn16, Corn53; http://dx.doi.org/10.5061/ dryad.t215b).

Mitochondrial Data Analysis. We conducted phylogenetic analyses for the $16 \mathrm{~S}$ mtDNA sequence data using maximum likelihood (ML) and Bayesian analysis. The $16 \mathrm{~S}$ tree was outgroup rooted with the sister group Cophixalus infacetus and Cophixalus zweifeli (Hoskin 2004). We ran a ML search using RAxML Blackbox (Stamatakis et al. 2008). Bayesian phylogenetic analyses were conducted using MRBAYES, version 3.04b (Huelsenbeck and Ronquist 2001). We produced posterior probability distributions by allowing four incrementally heated Markov chains to proceed for 20 million generations, sampling every 1,000 generations. The Bayesian posterior probability values were estimated from the sampled trees that remained after burnin samples were discarded. Because both the ML and the Bayesian tree topologies were the same, we have included only the ML tree with both the ML bootstraps and Bayesian posterior probabilities. Using Arlequin, version 3.1 (Excoffier et al. 2005), we estimated nucleotide diversity $\left(\theta_{s}, \theta_{\pi}\right)$ and net sequence divergence among populations $\left(D_{\mathrm{a}}\right)$ using the Tamura-Nei model of sequence divergence. We also calculated Fu's $F_{s}$ values in order to test for population expansion within lineages.
To estimate divergence times among major lineages, we used BEAST, version 1.4.8 (Drummond et al. 2005; Drummond and Rambaut 2007), with the GTR $+\mathrm{I}+\Gamma$ model of substitution, as this was the best-fit model of nucleotide substitution according to Modeltest (Posada and Crandall 1998). We assumed a substitution rate of $0.092 \pm 0.046$ substitutions per site per $100 \mathrm{Myr}$ for 16S (Roelants et al. 2007). Genealogies and model parameters for each lineage were sampled every one-thousandth iteration for 50 million generations under a relaxed lognormal molecular clock with uniformly distributed priors. Effective sample size (ESS) values were $>200$, suggesting convergence of the sampled parameters (Weinstock et al. 2005). ESS values and demographic plots for the analyses were assessed in Tracer, version 1.4.1 (Rambaut and Drummond 2007).

Nuclear Data Analysis. For nuclear sequences that were heterozygous for insertions or deletions, unphased haplotypes were inferred using CodonCode Aligner. Each sample was compared with several reference sequences and manually checked to reduce error. To identify haplotypes from heterozygous individuals, we used PHASE, version 2.1 (Stephens et al. 2001). We ran each locus three times to compare the phased positions. Unique haplotype numbers were assigned to each phased nuclear locus. To infer the number $(K)$ and composition of genetic populations, we used the Bayesian assignment program STRUCTURE, version 2.1 (Pritchard et al. 2000). Ten iterations were run for each value of $K$ from 1 through 10 . We implemented the admixture ancestry model and assumed correlated allele frequencies among populations, with a burn-in of 50,000 and a Markov chain Monte Carlo length of $1,000,000$. We used both visual inspection of changes in likelihood with increasing $K$ and the method described by Evanno et al. (2005) to identify the optimal number of clusters in our data set. We considered individuals to be admixed if the individual's estimated membership was $\leq 0.8$ at the "best" $K$. Admixed individuals were found in only extremely narrow zones of contact, and then in only a few populations. Because our primary interest was in identifying lineages and relationships among them, we excluded the few populations with admixed individuals in the following analyses. For each genetic population identified by STRUCTURE, we estimated diversity and divergence as described for mtDNA. To visualize overall divergence patterns, the resulting $D_{\mathrm{a}}$ matrix was then used to produce an unrooted population phylogram via the neighbor-joining algorithm in PAUP ${ }^{*}$, version 4 (Swofford 2003).

Combined Data Analysis. To estimate the current growth rates of the lineages and subgroups, we used LAMARC, version 2.1.3 (Kuhner 2006). For each sample, we used a 
combined data set of the mtDNA and the phased nDNA to estimate this parameter. Each locus was analyzed as a separate genomic region, and the results were integrated over these. We used the Bayesian analyses with 100,000 final recorded parameter sets, with a burn-in of 40,000 and sampling every 100 . The GTR nucleotide evolutionary model was used for all loci, and Modeltest GTR rates and base frequencies were supplied. We adjusted the upper limit of the growth rate to 8,000 and the lower limit to $-5,000$. Populations that were smaller in the past but that now show evidence of expansion will have positive values of the growth rate $g$. Conversely, negative $g$ indicates that a population was larger in the past.

\section{Phenotypic Analyses}

The genetic analyses (below) revealed three major monophyletic lineages: Central $(\mathrm{C})$, North $(\mathrm{N})$, and Hinchinbrook Island $(\mathrm{H})$. We analyzed phenotypic variation among these major lineages because they are supported under all genetic analyses. Analyses also testing variation among subgroups within $\mathrm{C}$ (not presented here) did not alter conclusions at the major lineage level. Only data for mature males (captured calling) were analyzed (morphological analyses: $n=511$ from 42 sites; call analyses: $n=197$ from 26 sites). As was done for the molecular analyses, the few admixed sites were removed to avoid the inclusion of introgressed individuals in tests of amonglineage divergence. Analyses of body size and shape divergence were conducted using all five morphological traits, and call divergence was tested using all three call traits. Statistical analyses were performed in SPSS, version 18, and SAS, version 9.2. All traits were tested for normality, and transformations were performed where necessary. The phenotypic analyses aimed to determine whether differences in morphology or call could be detected among the three lineages after controlling for the effects of environmental variation within lineages. That is, how would the lineages differ in morphology and call if they existed in the same place? This enables insights into ecological divergence and the potential for premating isolation.

Accounting for Environmental Variation in Traits. The sources of environmental variation we accounted for were altitude and temperature variation. These have been identified in other studies (e.g., Gerhardt and Huber 2002; Hoskin et al. 2005), with the typical patterns being that frogs at higher altitudes are bigger (and bigger frogs have lower-pitched calls) and frogs calling at higher temperatures have faster pulse rates and shorter calls. Phenotypic variation due to these sources could confound the interpretation of an overall lineage effect. ANCOVAs were used to test covariance of morphological traits against altitude, and call traits against temperature and altitude (app. B, available online). All analyses were nested by site within lineage to account for among-site variation and were conducted on altitude or temperature means within groups, as this was the appropriate replicate level for effects and accounted for uneven sampling across the range of altitude or temperature data. All morphological traits and call dominant frequency and duration were dependent on altitude: at higher altitudes, frogs are bigger and therefore have lower-pitched and also longer calls (app. B). Call pulse rate and duration were dependent on temperature: as temperature increases, pulse rate increases and calls get shorter (app. B). These significant relationships were removed by taking the unstandardized residuals from a linear regression of the trait on the covariate (app. B) and using them in the following analyses (e.g., altitude-corrected SVL, temperature-corrected pulse rate).

Divergence among the Lineages. Multicollinearity was then tested among the covariate-corrected morphological traits and call traits. The five morphological traits had very high levels of correlation (all $C_{\mathrm{P}}>0.8$; table $\mathrm{B} 1$, available online). Because high multicollinearity may cause problems in subsequent multivariate analyses, the five morphological traits were transformed into five principal components (PCs) via a principal component analysis (PCA), using the correlations matrix (due to weight being on a different scale than the four length measurements). For highly correlated morphological measurements, PCA also has the benefit of transforming the data into biologically relevant axes of size (PC1) and shape (remaining PCs) variation (Jolliffe 2002). Loadings on each PC were reported for the trait that loaded most heavily and for any subsequent traits that loaded $>0.7$ times the value of the most heavily loaded trait (table B2, available online). The three call traits had low to moderate levels of correlation (highest correlation, $C_{\mathrm{P}}=0.5$; table $\mathrm{B} 3$, available online) and so were able to be used directly in the multivariate analyses.

To test the fixed effect of genetic lineage on body size, body shape, and mating call, analyses were performed using the MIXED procedure in SAS, version 9.2, with parameters estimated using maximum likelihood. All analyses were nested by site within lineage to account for among-site variation within lineages. Because of the unequal lineage sample sizes, the denominator degrees of freedom were estimated using the Kenward-Rogers method (SAS Institute 2010). To correctly perform MANOVAs to test the effect of genetic lineage on traits using the MIXED procedure, the lineage $\times$ trait model was compared with the null model that contained only the traits (Wright 1998). The difference in -2 log likelihoods between the two models was tested against a $\chi^{2}$ 


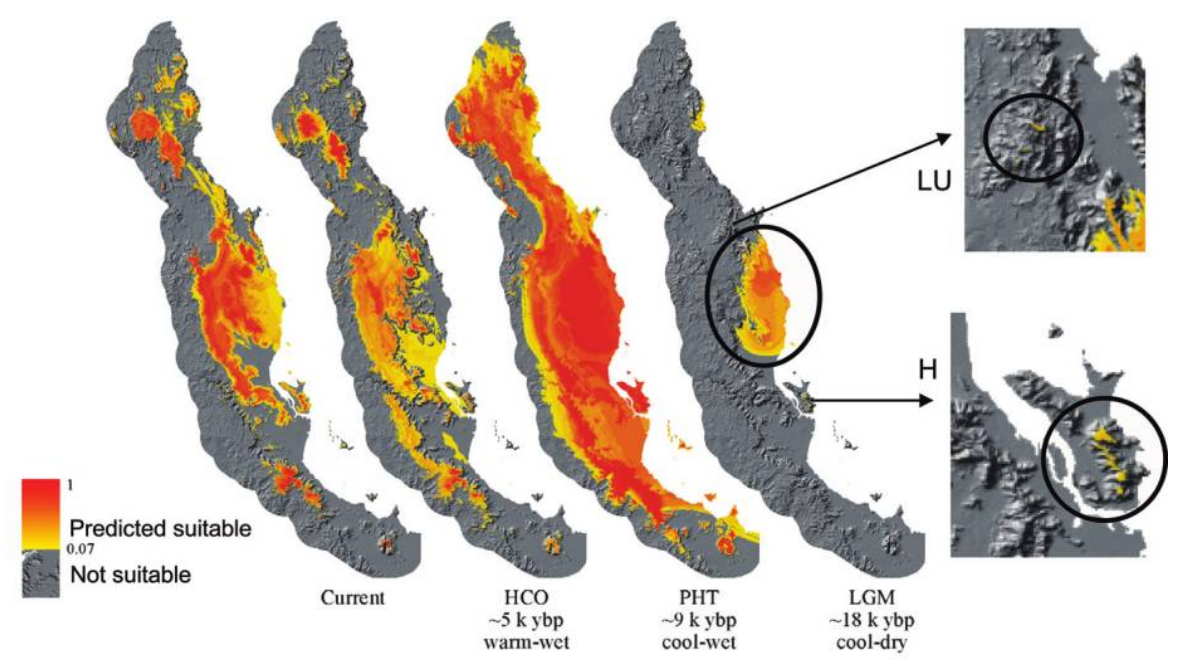

Figure 2: Maxent models of predicted distribution of Cophixalus ornatus (yellow-to-red scale) under current conditions (left) and under the following paleoclimates (from second left to right): the mid-Holocene (HCO; 5-3.5 kya, warm-wet), the Pleistocene-Holocene transition (PHT; 10-8 kya, cool-wet), and the Last Glacial Maximum (LGM; 18 kya, cool-dry), respectively. For the LGM models, very small predicted refugia in the uplands of Lamb Range (LU) and Hinchinbrook Island $(\mathrm{H})$ are shown in panels to the right.

distribution, with the degrees of freedom being the difference in number of parameters fitted between the two models.

Body size differences among the lineages were assessed by placing PC1, representing overall body size, in an ANOVA with pairwise contrasts specified to test differences between each of the lineages. Body shape differences among the lineages were assessed by placing the four remaining PCs (PC2-PC5) into a MANOVA with multivariate pair-wise contrasts specified in the lineage $\times$ trait model to test differences between each of the lineages. Univariate ANOVAs with pairwise contrasts were also conducted to test variation in each PC among lineages. Mating-call differences among the lineages were assessed by placing the three call traits into a MANOVA with multivariate pair-wise contrasts specified in the lineage $\times$ trait model to test for differences between each of the lineages. All $P$ values reported were adjusted for multiple comparisons using the false discovery rate (FDR) method (Benjamini and Hochberg 1995). For graphical representation of the multivariate body shape and call divergence, we constructed a single canonical variate $(\mathrm{CV} 1)$ at the lineage level for each data set from a multivariate hierarchical linear model, with site nested within lineage. The respective canonical variate equations were then applied to PC2PC5 for body shape CV1 and to the three call traits for call CV1. These CVs represent the linear combination of traits that differ most among the lineages while accounting for among-site variation (shown in fig. 4).

\section{Results \\ Predicted Distributions under Current and Past Climates}

The Maxent model in the current climate was dominated by three climatic variables-positively by precipitation of the driest and wettest quarters and negatively by temperature of the wettest quarter-and produced a strong prediction relative to the known distribution $(\mathrm{AUC}=0.94$; fig. 1). Notably, Cophixalus ornatus is predicted to be absent from the montane rainforest in the Lee Uplands (LE), located between the southernmost-known populations in the Spec Uplands (SU) and those in the Kirrama Uplands (KU) to the north. Repeated surveys for C. ornatus at LE have failed to detect this species. However, the model does overpredict to multiple high-elevation rainforest areas to the north and to the south of the current distributional limits. The observed absence of C. ornatus from these climatically suitable areas, despite intensive surveys for microhylids, could relate to the presence of congeners (Hoskin 2004) or, more likely, limitations on dispersal across the drier forest barriers that separate these areas.

The paleomodels indicate considerable variation in the potential range of C. ornatus from the cool-dry LGM to the present (fig. 2), and parallel predicted responses of the rainforest itself (VanDerWal et al. 2009). At the LGM, the potential range is much reduced, especially in the southern and northern regions of the current range. Subsequently, the potentially suitable range expands during the cool-wet phase of the PHT, allowing for recolonization of northern 
and southern regions and expansion in the central region, and then it contracts to higher regions during the midHCO before achieving the current range. Continuously suitable areas within the current species range are mostly in the central AWT, with very small stable areas in the Lamb Uplands (LU) and on Hinchinbrook Island (H; fig. 2).

On the basis of the paleomodels, we can derive the following predictions for the genetic data: (1) the presence of multiple divergent lineages, reflecting persistence in the central AWT and in the small predicted refugia at LU and $\mathrm{H}$; (2) highest genetic diversity in the central AWT, reflecting the relatively large refugial area there; and (3) signatures of population expansion in northern and southern regions, due to expansion of populations from central refugia during the early Holocene, before connections were cut in the mid-Holocene to the present.

\section{Mitochondrial and Nuclear Phylogeography}

Phylogeographic structure of mtDNA was determined from 486 individuals for the $16 \mathrm{~S}$ rDNA gene segment across 42 localities (after pooling some geographically adjacent small samples), with an average of 11.8 individuals per locality (table $\mathrm{C} 1$, available online). For analyses of nuclear sequences, only individuals with a complete data set of four loci were used $(N=300$ individuals across 42 localities, averaging 7.3 individuals per locality; table $\mathrm{C} 1$ ). Analyses of these data revealed that $C$. ornatus is highly genetically structured in the manner predicted by the paleomodels above (fig. 3; tables 1,2).

Mitochondrial Phylogeography and Diversity. The sequenced and aligned segment of the 16S rDNA gene spanned 513 nucleotide positions. The ML analysis revealed three geographically structured lineages, each with strong support (fig. 3B). Geographically these span the northern $(\mathrm{N})$, central-southern $(\mathrm{C})$, and Hinchinbrook Island $(\mathrm{H})$ populations (figs. $3 \mathrm{~A}, \mathrm{C} 1$ ). Within the $\mathrm{C}$ lineage there is considerable heterogeneity and spatial structure, with distinct subgroups representing the Lowland (L) and Southern (S) populations, and a heterogeneous subgroup (BF) across Mount Bartle Frere, Mount Bellenden Ker, and the high areas of the coastal Malbon Thompson Range (figs. $3 A, 3 B, C 1$ ). Remarkably, all of these lineages and subgroups, other than the one on Hinchinbrook Island, meet in the rainforests on and around Mount Bartle Frere (fig. $3 A$, inset), which is the highest $(1,622 \mathrm{~m})$ mountain in the region and a major predicted refuge. Net sequence divergence $\left(D_{\mathrm{a}}\right)$ among the three major lineages was $4 \%-$ $6 \%$, whereas among subgroups of the C clade, $D_{\mathrm{a}}$ varied from $2 \%$ to $4 \%$ (table 2 ). As expected from the paleomodeling, within-population nucleotide diversity $\left(\theta_{\pi}\right.$ ex- pressed as percentage) was an order of magnitude lower for the $\mathrm{N}$ and $\mathrm{H}$ lineages $(0.36 \%$ and $0.24 \%$, respectively) than in the C lineage (2.70\%; table 1). Analysis of molecular variance (AMOVA) indicated substantial variation, both among the three major lineages $(71 \%, P<.001)$ and among populations within subgroups $(28 \%, P<.001)$. Within both the $\mathrm{N}$ and the $\mathrm{C}$ lineages there is strong partitioning of sequence diversity among sampled populations ( $47 \%$ and $97 \%$, respectively; $P<.001$ for both).

Estimated times of divergence among the three major lineages substantially predate the LGM (defined as $\sim 18$ kya; Hopkins et al. 1993; Kershaw et al. 2005), with point estimates in the Pliocene but broad confidence limits (fig. C2 in the online edition of the American Naturalist). The North and Central/Hinchinbrook Island lineages are estimated to have diverged at 4.7 million years ago (mya; 95\% highest posterior densities [HPD], 2.6-8 mya) and the Central and Hinchinbrook Island lineages at 3.4 mya (95\% HPD, 1.8-5.5 mya).

Nuclear Phylogeography and Diversity. Clustering of individuals' four-locus genotypes using STRUCTURE revealed fine-scale population structure that was generally consistent with the mtDNA results and narrow zones of admixture/introgression at parapatric boundaries between the lineages (fig. 3D). One exception was the small sample $(N=4)$ from Hinchinbrook Island that proved to be of unstable affinity in repeated runs and was subsequently excluded from this part of the analysis (data not shown). This population is highly divergent in the other genetic analyses (see below). Using STRUCTURE, the posterior probability $(\ln \operatorname{Pr}(X \mid K))$ values increase abruptly from the $K=1$ group to the $K=2$ group and then more gradually to $K=5$, beyond which the values plateau at $K=8$ (fig. C3, available online). Using the Evanno et al. (2005) method, we found the highest $\Delta K$ value at $K=2$ (fig. C4, available online), in which group 1 corresponds to populations with $\mathrm{N}$ mtDNA lineages and group 2 corresponds to populations with $\mathrm{C}$ mtDNA lineages. At higher $K$ values, the $\mathrm{C}$ mtDNA lineage splits, first $(K=3)$ into populations with $\mathrm{L}$ or BF mtDNA versus those with BF or $\mathrm{S}$ mtDNA. Then at $K=4$, the Lowland mtDNA populations (group 3) separate from the main BF mtDNA group and at $K=5$ the BF/S mtDNA group splits into two geographic components, one (group 4) adjacent to Mount Bartle Frere with mostly BF but also some $\mathrm{S}$ mtDNA and the other (group 5) from the central Atherton Uplands to the southern limit of the range with only $\mathrm{S}$ mtDNA (fig. $3 D$ ). At both $K=4$ (the number of lineages and subgroups detected in the mtDNA analysis, excluding $\mathrm{H}$ ) and $K=5$, there are narrow zones of admixture/introgression (fig. $3 D$ ). Geographic transition is particularly abrupt between the $\mathrm{N}$ and $\mathrm{C}$ mtDNA lineages. More introgression is evi- 


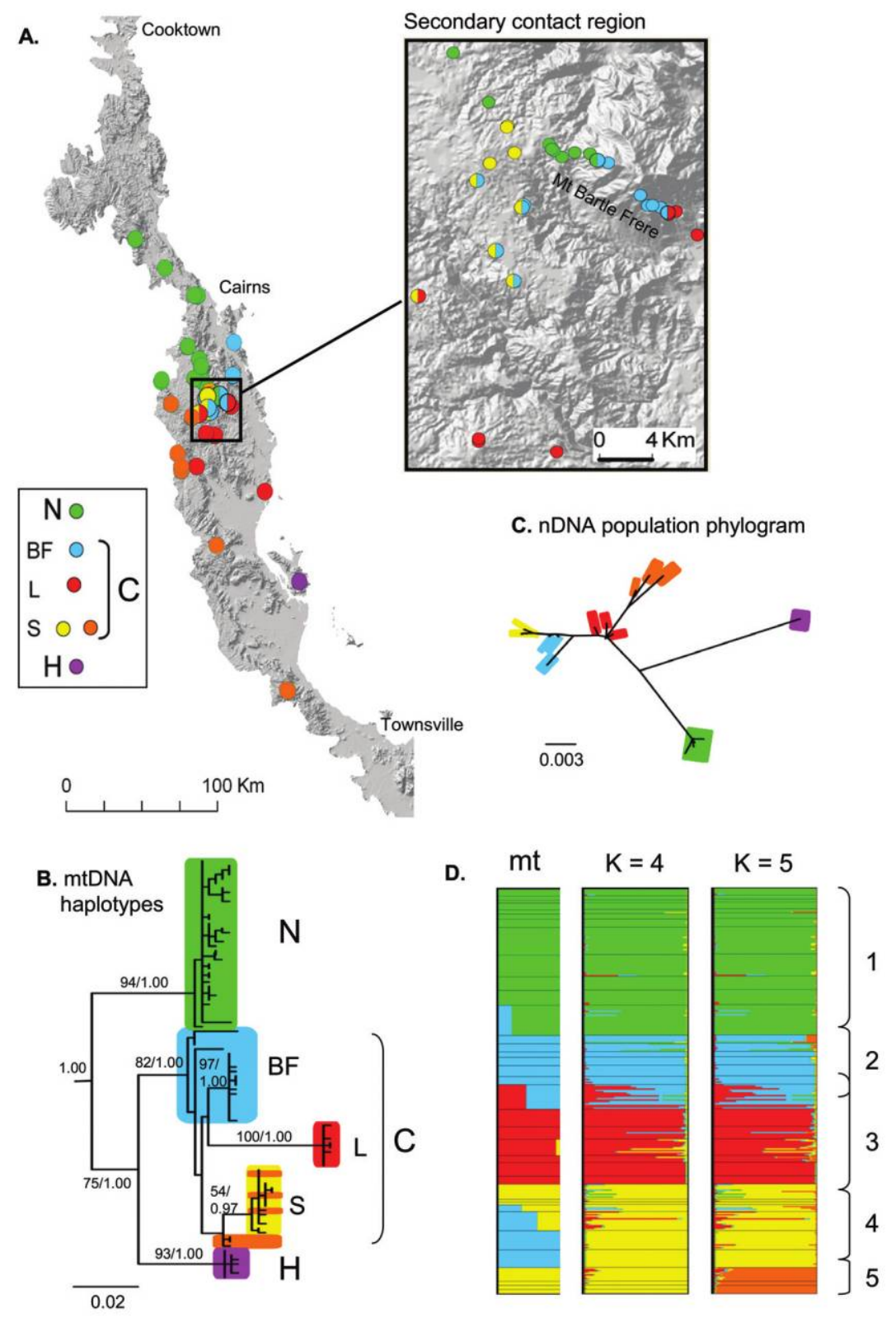

Figure 3: Lineage structure in Cophixalus ornatus. Colors correspond to the three major lineages (Hinchinbrook Island [H], North $[\mathrm{N}]$, and Central $[\mathrm{C}]$ ) and the subgroups within $\mathrm{C}$ (Mount Bartle Frere [BF], Lowland [L], and Southern [S]). A, Map of the Australian Wet Tropics showing localities sampled for molecular analyses. Colored dots on the map represent the lineage as determined by molecular analyses of four nuclear loci and one mitochondrial locus. Mixed-color dots represent admixed sites. The inset shows the region of secondary contact around Mount Bartle Frere. For site details, see figure C1, available online. $B, 16 \mathrm{~S}$ mtDNA maximum likelihood tree. Values above the slash are RAxML bootstrap values; values below the slash are Bayesian posterior probabilities. C, Population phylogram based on neighbor-joining of pairwise $D_{\mathrm{a}}$ values. $D$, Genetic structure per sampled site. Individuals are arranged according to latitude within mitochondrial lineages. Black lines denote each site, with vertical separation proportional to the number of individuals sampled; colored lines represent individuals, with the color of each representing the proportion of that individual's membership in each cluster. Left, average mitochondrial proportion per site. Right, STRUCTURE clustering of individual four-locus nuclear genotypes for $K=4$ and $K=5$ groups. Potential hybrid individuals are depicted as bars with obvious contributions from two colors. The $\mathrm{H}$ lineage was not included in these analyses (see text). 
Table 1: Genetic results for major lineages and genetic subgroups of Cophixalus ornatus

\begin{tabular}{|c|c|c|c|c|c|c|c|c|c|c|}
\hline \multirow{2}{*}{$\begin{array}{l}\text { Major lineage, } \\
\text { subgroup }\end{array}$} & \multicolumn{5}{|c|}{ mtDNA } & \multicolumn{4}{|c|}{ nDNA } & \multirow[b]{2}{*}{$g(95 \% \mathrm{CI})$} \\
\hline & $N_{\mathrm{p}}$ & $N_{s}$ & $\theta_{\pi}$ & $\theta_{\mathrm{s}}$ & Fu's $F_{s}$ & $N_{\mathrm{p}}$ & $N_{\mathrm{s}}$ & $\theta_{\pi}$ & $\theta_{\mathrm{s}}$ & \\
\hline $\mathrm{N}$ & 14 & 8.3 & .36 & .88 & -27.69 & 11 & 7.8 & .34 & .70 & $406(-19$ to 692$)$ \\
\hline $\mathrm{H}$ & 1 & 8.0 & .24 & .31 & -9.75 & 1 & 4.0 & .37 & .33 & $2,071$ (660 to 3,404$)$ \\
\hline $\mathrm{C}:$ & 19 & 10.6 & 2.70 & 1.70 & -23.93 & 18 & 6.7 & .86 & .76 & $81(-43$ to 286$)$ \\
\hline $\mathrm{BF}$ & 8 & 11.8 & .34 & .77 & -27.94 & 6 & 5.2 & .41 & .40 & $65(-145$ to 440$)$ \\
\hline $\mathrm{L}$ & 5 & 14.2 & .03 & .08 & $-3.4 \times 10^{38}$ & 5 & 8.2 & .60 & .41 & $168(-26$ to 678$)$ \\
\hline$S$ & 6 & 5.8 & .56 & .63 & -26.33 & 7 & 5.9 & .82 & .71 & $-18(-182$ to 184$)$ \\
\hline
\end{tabular}

Note: Only lineage $\mathrm{C}$ has subgroups. $N_{\mathrm{p}}$, total number of sampled populations with a majority of "pure" individuals; $N_{\mathrm{s}}$, mean sample size per population. Diversity measures are based on variable sites $\left(\theta_{\mathrm{s}}\right)$ and pairwise divergence $\left(\theta_{\pi}\right)$. All Fu's $F_{\mathrm{s}}$ values indicate significant population expansion $(P<.05) . g$, exponential growth rate; $95 \%$ confidence intervals (CIs) of $g$ were calculated from LAMARC using mtDNA + nDNA. BF, Mount Bartle Frere; C, Central-Southern; H, Hinchinbrook Island; L, Lowland; N, Northern; S, Southern.

dent between the subgroups of $\mathrm{C}$, with admixed individuals at parapatric boundaries between the $\mathrm{BF}, \mathrm{L}$, and $\mathrm{S}$ mtDNA subgroups (fig. $3 D$ ). Given the small number of nuclear loci examined, these are likely to be conservative estimates of admixture (e.g., there is low power to detect backcrosses). Accordingly, we removed entire sites that had individuals that were identified as admixed from the following analyses. All other individuals were included in the analyses.

The resulting combined nuclear data set contained 1,152 nucleotide positions across the four loci and 192 nonadmixed individuals from 29 locations. The unrooted population phylogram produced using the molecular distances from the nuclear sequences (fig. $3 C$ ) was congruent with the mitochondrial phylogeny (fig. $3 B$ ) in that the $\mathrm{N}$ and $\mathrm{H}$ lineages were highly distinct from each other and from the $\mathrm{C}$ samples. The Central lineage is genetically diverse, and the major genetic populations identified by STRUCTURE at $K=5$ were clustered in the phylogram. Populations on the western flank of Mount Bartle Frere (group 4, with BF, S, or both mtDNA types) clustered with the geographically proximal populations (group 2, BF mtDNA) and were distinct from the populations to the south (group 5, S mtDNA). For subsequent analyses, group 2 and group 4 populations are grouped as the $\mathrm{BF}$ subgroup despite the presence of some individuals with $\mathrm{S}$ mtDNA.

Similar to mtDNA, net sequence divergences at nuclear genes were higher between the major $\mathrm{N}, \mathrm{C}$, and $\mathrm{H}$ lineages $\left(D_{\mathrm{a}}\right.$ values between $1.7 \%$ and $2.7 \%$ ) than among the $\mathrm{C}$ subgroups $(<0.6 \%$; table 2$)$. Likewise, the $\mathrm{C}$ lineage had much higher nuclear sequence diversity $\left(\theta_{\pi}=0.86 \%\right)$ than did either the $\mathrm{N}(0.34 \%)$ or the $\mathrm{H}(0.37 \%)$ lineage (table 1). AMOVA indicated substantial variation both among the three major lineages $(68 \%, P<.001)$ and among populations within subgroups $(18 \%, P<.001)$.
Population Expansion. For mtDNA alone, all lineages (N, $\mathrm{C}$, and $\mathrm{H}$ ) and each of the subgroups within $\mathrm{C}$ had significantly negative $F_{\mathrm{s}}$ values (table 1), indicating historical population expansions across the range of the species. The coalescent analysis of combined mtDNA and nuclear loci (LAMARC) indicated positive population growth (positive values of $g$ ) for all lineages and subgroups except L (table 1). However, it was only for $\mathrm{H}$, the group with the highest point estimate, that the $95 \%$ confidence interval excluded 0 (table 1). Thus, for the major lineages $\mathrm{H}$ shows a strong population expansion signature, but for the other lineages evidence is mixed.

To test the hypothesis that $\mathrm{N}$ persisted in a small northern refuge (e.g. LU in fig. 2) as opposed to expanding from the periphery of the major central refuge, we assessed expansion signatures across $\mathrm{N}$ populations. We grouped populations north of LU (fig. C1; populations 1-3), populations around LU (fig. C1; populations 5-7), and two groups of populations south of LU (fig. C1; populations 8,9 , and 11-14). For mtDNA, only the most southerly $\mathrm{N}$ populations (11-14) showed range expansion $\left(F_{\mathrm{s}}=-2.1, P<.05\right)$. Combined Lamarc analyses on both the mitochondrial and the nuclear data indicated positive population growth in each of the two groups south of LU (populations 8 and $9, g=1,223$ [95\% HPD, 348-10,108]; populations $11-14, g=1,018$ [95\% HPD, 315-3,385]). By contrast, in populations around and north of LU there was no such evidence for population expansion. The results support the interpretation that the $\mathrm{N}$ lineage persisted in a separate refuge (LU or farther north) rather than expanding northward from the central refuge.

Summary of Genetic Results. The combined mtDNA and nuclear gene evidence supports the presence of three major lineages: northern $(\mathrm{N})$ versus central-southern $(\mathrm{C})$ populations on the mainland and the Hinchinbrook Island 
Table 2: Corrected net sequence divergence $\left(D_{\mathrm{a}}\right)$ between Cophixalus ornatus lineages and subgroups

\begin{tabular}{|c|c|c|c|c|c|c|c|c|c|c|}
\hline \multirow[b]{2}{*}{ Major lineage, subgroup } & \multicolumn{5}{|c|}{ mtDNA } & \multicolumn{5}{|c|}{ nDNA } \\
\hline & $\mathrm{H}$ & $\mathrm{C}$ & $\mathrm{BF}$ & $\mathrm{L}$ & S & $\mathrm{H}$ & $\mathrm{C}$ & $\mathrm{BF}$ & $\mathrm{L}$ & S \\
\hline $\mathrm{N}$ & .061 & .054 & .052 & .090 & .056 & .027 & .017 & .020 & .016 & .020 \\
\hline $\mathrm{H}$ & & .041 & .050 & .061 & .045 & & .025 & .028 & .023 & .028 \\
\hline C: & & & $\mathrm{n} / \mathrm{a}$ & $\mathrm{n} / \mathrm{a}$ & $\mathrm{n} / \mathrm{a}$ & & & $\mathrm{n} / \mathrm{a}$ & $\mathrm{n} / \mathrm{a}$ & $\mathrm{n} / \mathrm{a}$ \\
\hline $\mathrm{BF}$ & & & & .044 & .026 & & & & .005 & .002 \\
\hline $\mathrm{L}$ & & & & & .043 & & & & & .006 \\
\hline
\end{tabular}

Note: Only lineage $\mathrm{C}$ has subgroups. Redundant columns and rows have been removed. n/a, not available. BF, Mount Bartle Frere; C, Central; H, Hinchinbrook Island; L, Lowland; N, Northern; S, Southern.

(H) population. The $\mathrm{C}$ lineage has the highest diversity, with relatively clear demarcation between Lowland (L), Mount Bartle Frere area (BF), and Southern (S) populations. All major lineages and subgroups of $C$ show evidence of population expansion for mtDNA, whereas coalescent estimates from combined mtDNA and nDNA demonstrate population growth for $\mathrm{H}$ alone. Finer-scale tests of population expansion within the $\mathrm{N}$ lineage suggest persistence in the north of the range and subsequent expansion south. The $\mathrm{N}$ and $\mathrm{C}$ lineages form a very tight parapatric boundary, whereas there is more evidence for admixture among the subgroups within $\mathrm{C}$, especially between the $\mathrm{BF}$ and $\mathrm{S}$ subgroups.

\section{Phenotypic Divergence}

Divergence in Body Size and Shape. The PCA on the five altitude-corrected morphological traits resulted in a PC1 that accounted for $87.8 \%$ of variation and was loaded equally, strongly, and positively by all five traits (average 0.937 ), and that therefore represented body size. The next four PCs accounted for $4.6 \%, 3.5 \%, 2.3 \%$, and $1.7 \%$ of the variation, respectively, and represented body shape variation (table B2). Body size variation (PC1) among the lineages was tested separately from body shape variation (PC2-PC5). The site-nested ANOVA on PC1 revealed highly significant body size divergence among the three lineages $\left(F_{2,44.6}=25.28, P_{\text {false discovery rate }[\mathrm{FDR}]}<.0001\right)$. The planned contrasts revealed that $\mathrm{H}$ frogs are significantly smaller in overall body size than both $\mathrm{N}\left(F_{1,47.5}=45.09\right.$, $\left.P_{\mathrm{FDR}}<.0001\right)$ and $\mathrm{C}\left(F_{1,49.8}=43.82, P_{\mathrm{FDR}}<.0001\right)$ frogs, whereas $\mathrm{N}$ and $\mathrm{C}$ frogs do not differ in body size (fig. $4 A$; table B4, available online). A site-nested ANOVA on a larger data set of altitude-corrected SVL confirmed this result, also showing highly significant size variation among the three lineages $\left(F_{2,41.9}=30.01, P_{\mathrm{FDR}}<.0001\right)$, with $\mathrm{H}$ frogs being smaller than $\mathrm{N}$ and $\mathrm{C}$ frogs (for both pairwise contrasts, $\left.P_{\mathrm{FDR}}<.001\right)$ while $\mathrm{N}$ and $\mathrm{C}$ frogs did not differ in size $\left(P_{\mathrm{FDR}}=.0959\right.$; table $\left.\mathrm{B} 4\right)$. The site-nested MANOVA on PC2-PC5 showed significant body shape variation among the lineages (likelihood ratio $\chi^{2}=20.95, \mathrm{df}=8$,
$\left.P_{\mathrm{FDR}}=.0134\right)$. The planned contrasts revealed that the $\mathrm{N}$ frogs differ significantly in body shape from both $\mathrm{H}$ $\left(F_{4,40.5}=3.64, \quad P_{\mathrm{FDR}}=.0210\right)$ and $\mathrm{C} \quad\left(F_{4,34.9}=3.09\right.$, $\left.P_{\mathrm{FDR}}=.0420\right)$ frogs, while $\mathrm{H}$ and $\mathrm{C}$ frogs did not differ in body shape (fig. $4 B$; table B4). In the site-nested ANOVAs on the individual PCs, only PC2 varied significantly among the lineages $\left(F_{2,45.3}=3.59, P_{\mathrm{FDR}}=.0492\right)$, with $\mathrm{N}$ frogs having relatively smaller finger disks than $\mathrm{C}$ frogs relative to body size (planned contrast $F_{1,40.4}=$ 6.89, $P_{\mathrm{FDR}}=.0209$; table B4).

Divergence in Mating Call. The site-nested MANOVA on the three call traits revealed highly significant call divergence among the lineages (likelihood ratio $\chi^{2}=43.48$, $\left.\mathrm{df}=3, P_{\mathrm{FDR}}<.0001\right)$. The multivariate planned contrasts revealed that all three lineages differ significantly from each other, with $\mathrm{N}$ frogs being highly significantly different from both $\mathrm{H}\left(F_{3,24.5}=21.97, P_{\mathrm{FDR}}<.0001\right)$ and $\mathrm{C}\left(F_{3,25.1}=\right.$ 14.71, $\left.P_{\mathrm{FDR}}<.0001\right)$ frogs, and $\mathrm{H}$ and $\mathrm{C}$ frogs differed, but to a lesser extent $\left(F_{3,22.5}=8.40, P_{\mathrm{FDR}}=.0016\right.$; fig. $4 C$; table B4). Nested univariate ANOVAs revealed that all three call traits differ significantly among the lineages (DF: $F_{2,26}=$ $16.68, P_{\mathrm{FDR}}<.0001 ;$ DUR: $F_{2,26.3}=5.22, P_{\mathrm{FDR}}=.0195$; PULSE: $\quad F_{2,21.4}=11.35, \quad P_{\mathrm{FDR}}=.0009 ;$ table B4). The planned contrasts revealed the following (table B4): $\mathrm{H}$ frogs have calls of significantly higher dominant frequency than $\mathrm{C}$ frogs, which in turn have calls of significantly higher dominant frequency than $\mathrm{N}$ frogs. $\mathrm{H}$ frogs have significantly shorter duration calls than $\mathrm{N}$ frogs. Call duration for $\mathrm{C}$ frogs is between that of $\mathrm{H}$ and $\mathrm{N}$ frogs and is almost significantly different from that of each. $\mathrm{N}$ frogs have calls of significantly faster pulse rates than those of both $\mathrm{H}$ and $\mathrm{C}$ frogs, which do not differ from each other in pulse rate.

Summary of Phenotypic Divergence among Lineages. Body size differs significantly among the lineages: $\mathrm{H}$ frogs are significantly smaller than $\mathrm{N}$ and $\mathrm{C}$ frogs, whereas $\mathrm{N}$ and $\mathrm{C}$ frogs do not differ in size (fig. 4A). Body shape differentiates $\mathrm{N}$-lineage frogs from $\mathrm{H}$ and $\mathrm{C}$ frogs, which do not differ from each other in terms of body shape (fig. 

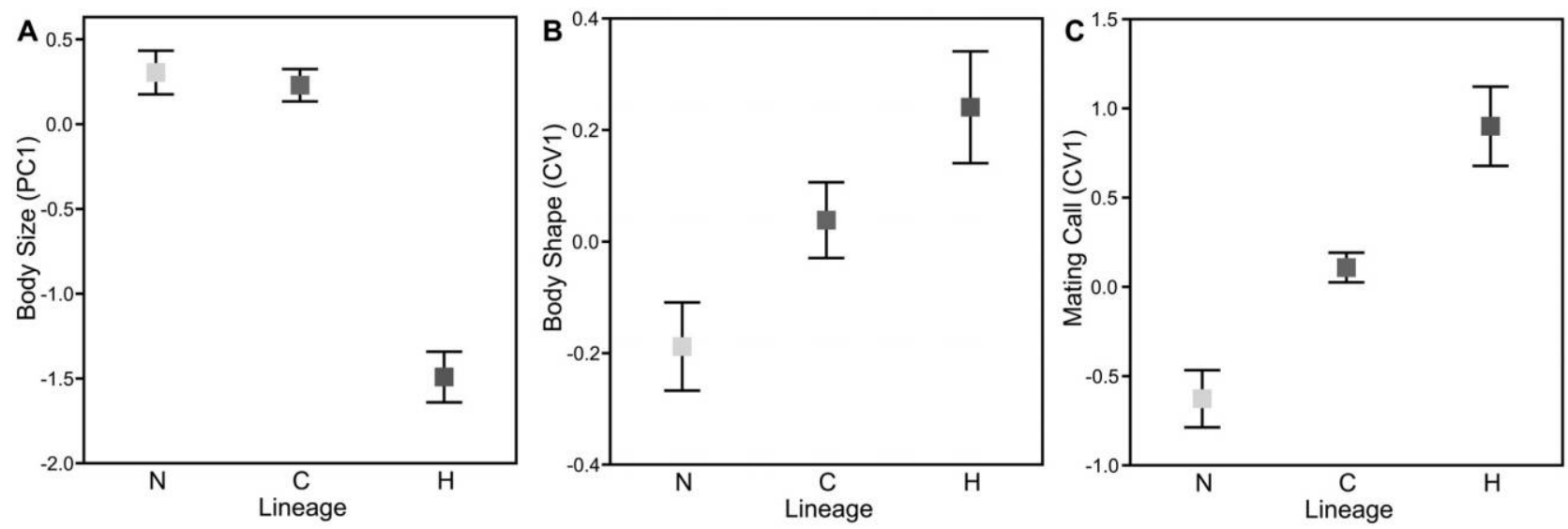

Figure 4: Variation in body size $(A)$, body shape $(B)$, and mating call $(C)$ among the major lineages of North $(\mathrm{N})$, Central $(\mathrm{C})$, and Hinchinbrook Island $(\mathrm{H})$. Squares represent lineage means and error bars are 95\% confidence intervals based on individuals; panels are graphical representations of the nested univariate analysis of PC1 $(A)$, the nested multivariate analysis of PC2-PC5 $(B)$, and the nested multivariate analysis of dominant frequency, call duration, and pulse rate $(C)$. The canonical variate $(\mathrm{CV} 1)$ axes in $B$ and $C$ represent the linear combination of traits that differ most among lineages for each analysis, while accounting for among-site variation.

$4 B)$. The mating calls of $\mathrm{H}, \mathrm{N}$, and $\mathrm{C}$ frogs differ significantly, with the greatest divergence being between $\mathrm{H}$ and $\mathrm{N}$ frog calls and those of $\mathrm{C}$ frogs being intermediate (fig. 4C). Dominant frequency differs between all three lineages, duration differs between $\mathrm{H}$ and $\mathrm{N}$ frogs, and $\mathrm{N}$ frogs differ from $\mathrm{H}$ and $\mathrm{C}$ frogs in terms of pulse rate.

\section{Discussion}

Our results strongly suggest that historic fragmentation of populations due to climatic shifts shaped the current genetic and phenotypic diversity in Cophixalus ornatus. Our original predictions were satisfied by (1) spatial correlation between major lineage structuring and predicted persistence: populations of $C$. ornatus cluster as three major lineages $(\mathrm{C}, \mathrm{N}$, and $\mathrm{H})$ that correlate spatially with predicted paleorefugia; (2) higher genetic diversity in regions of persistence, particularly where these regions were larger: the $\mathrm{C}$ lineage, which is associated with a predicted large, spatially complex central refuge, has high genetic diversity relative to the two lineages associated with two very small peripheral paleorefugia; (3) genetic signatures of population expansion from paleorefugia, particularly where these are predicted to have been small: all populations show evidence of population expansion but it is most pronounced for the $\mathrm{H}$ populations and the southern populations of $\mathrm{N}$; and (4) divergence in ecologically important phenotypic traits among refugia: phenotypic variation was structured concordant with major phylogeographic lineages.

\section{The Role of Climate Shifts in Shaping Genetic Diversity}

As was found for other studies (e.g., Hugall et al. 2002; Knowles et al. 2007; Walker et al. 2009), there is a strong correlation between patterns of current genetic diversity in C. ornatus and the location of predicted paleorefugia. The genetic results concord with predicted persistence of populations of $C$. ornatus through the LGM in a large, spatially complex central refuge and two very small peripheral refugia (LU and Hinchinbrook Island). The spatial scale of structuring in C. ornatus more closely resembles that of invertebrates (e.g., snails, beetles, spiders) in the AWT and other systems (e.g., Hugall et al. 2002; Bell et al. 2007; Boyer et al. 2007; Starrett and Hedin 2007; Bond and Stockman 2008; Walker et al. 2009) than other AWT vertebrates, which generally show fewer, broadly spread lineages correlating to core predicted northern and southern refugia (Joseph et al. 1995; Schneider et al. 1998; Moritz et al. 2009). This probably reflects the high persistence and low vagility of this small, terrestrial-breeding frog. Elsewhere in the world, other small-bodied, terrestrialbreeding rainforest amphibians provide examples of particularly pronounced fine-scale phylogeographic and species diversity (e.g., Meegaskumbura et al. 2002; Roberts et al. 2006; Köhler and Günther 2008; Vieites et al. 2009).

The central lineage $(\mathrm{C})$ consists of several subgroups (BF, S, and L) that likely persisted in the large predicted areas of montane rainforest and associated lowlands in the central AWT. The genetic results and spatial modeling suggest that the $\mathrm{N}$ and $\mathrm{H}$ lineages persisted in very small refugia. In contrast to other AWT vertebrates, the paleo- 
models do not suggest that $C$. ornatus persisted at $\mathrm{CU}$, its northern limit, but rather that it persisted in LU (fig. 2). Genetic tests of population expansion support persistence of the $\mathrm{N}$ lineage in the northern half of its range with subsequent (most likely early Holocene; fig. 2) expansion southward. An alternative is persistence in a small lowland area predicted to the northeast of $\mathrm{CU}$ (figure 2), but this is unlikely given that it is well outside the current range. Particularly interesting is the long-term persistence of $C$. ornatus on Hinchinbrook Island. Paleomodeling suggests that rainforest persisted only in very small upland isolates on Hinchinbrook Island during climatically restrictive periods (e.g., the LGM; fig. 2; VanDerWal et al. 2009). Genetic signatures of population expansion are particularly evident in this lineage. Despite repeated land connections to the mainland over at least the last few million years, there would have been limited potential for historical contact between $\mathrm{H}$ and $\mathrm{C}$ populations because these connections were dominated by dry forest types (Nix 1991; VanDerWal et al. 2009).

The correlation between the genetic data and predicted distribution at the LGM suggests that late Pleistocene glacial cycles determined the persistence of lineages and shaped current patterns of genetic diversity within them. However, as was found in many other studies (Klicka and Zink 1997; Avise and Walker 1998; Moritz et al. 2000; Rull 2008; Moussalli et al. 2009), divergence times among the major lineages well precede the LGM, with estimates suggesting Pliocene divergences between N, C, and $\mathrm{H}$ frogs. This suggests that the late Pleistocene models used here also predict persistence and isolation over much longer time periods and that previous climatic oscillations resulted in spatially congruent refugia (see also Bell et al. 2010). Paleomodeling is restricted to the LGM and the Holocene because pollen-derived paleoclimate estimates for the AWT are restricted to this period (Kershaw and Nix 1988). However, detailed paleobotanical data for the region shows long-term presence of rainforest, with fluctuations in extent and composition from the mid-Miocene onward (Greenwood and Christophel 2005; Kershaw et al. 2005), overlain on geologically ancient and stable landforms (Nott 2005). Therefore, at least for the AWT, refugial areas predicted for the LGM are likely indicative of those present throughout restrictive periods of the Miocene (Greenwood and Christophel 2005; Kershaw et al. 2005) and through climatic cycles of the Plio-Pleistocene (Haffer 1997).

The big question this pre-Pleistocene model presents is how did such genetic (and phenotypic; see below) divergence accumulate in the face of regular opportunities for gene flow? This question has been raised for other regions in regard to repeated connections during the Pleistocene (Zink and Slowinski 1995; Hewitt 2000; Knowles 2000;
Futuyma 2010), and it has been suggested that divergence and speciation requires rapid evolution of reproductive isolation between lineages such that mixing does not occur during subsequent interglacials (Knowles 2000; Carstens and Knowles 2006). It is clear that in our system there was ample opportunity for mixing during interglacial climates (at least between $\mathrm{N}$ and $\mathrm{C}$ frogs; figure 2). However, we suggest that the core populations in refugial areas may not have been exposed to introgression through time because the intervening mixed populations would have become extinct every time rainforest "contracted" to refugia. The core populations could therefore diverge unimpeded by gene flow. This suggestion requires testing in the AWT and other such systems and will depend on a range of factors, including distance between refugia, duration and extent of connection, dispersal abilities, and selection for or against loci. Estimating gene flow between core and intervening populations across a range of taxa under current expansive conditions would be insightful.

\section{The Role of Climate Shifts in Generating Phenotypic Diversity}

We found that phenotypic variation was structured concordant with major phylogeographic lineages, which suggests that it was similarly generated by historic fragmentation of populations to refugia. This raises the question of whether phenotypic divergence was generated by drift or selection. The null approach to phylogeographic studies is that of historical isolation across environmentally similar refugia. This idea of niche conservatism clearly plays a role in driving allopatric divergence-it is due to restriction to a particular habitat (and low vagility) that gene flow is severed when habitats fragment (Wiens and Graham 2005; Kozak and Wiens 2006) - but potentially not in driving phenotypic divergence and speciation over the shorter time periods generally associated with climatic oscillations. Across environmentally similar refugia, genetic divergence will accumulate with little accompanying phenotypic divergence through nonadaptive (drift) and adaptive (stabilizing or uniform selection) processes (Charlesworth et al. 1982; Coyne and Orr 2004; Wiens and Graham 2005; Nosil and Flaxman 2011). This appears to be the norm for AWT vertebrates, with studies generally failing to find phenotypic differences between phylogeographic lineages that occupied core northern and southern refugia (Schneider and Moritz 1999; Hoskin et al. 2005; Moritz et al. 2009). This contrasts with the substantial phenotypic divergence found within some of these lineages that is associated with habitat differences (Schneider et al. 1999) or reinforcing selection in regions of secondary contact (Hoskin et al. 2005).

Environmentally heterogeneous refugia on the other 
hand will more likely result in phenotypic divergence and speciation, with divergent selection among populations potentially leading to rapid divergence in ecological and/ or mating traits (Rice and Hostert 1993; McPeek 1996; Schluter 2001; Gavrilets 2003, 2004; Coyne and Orr 2004; Hoskin and Higgie 2010). Even weak selection (i.e., due to subtle differences in environment between refugia) can dramatically increase the rate of divergence when gene flow is absent or limited (Rice and Hostert 1993; Gavrilets 2003, 2004). We specifically chose traits relevant to ecology and mating, traits of key biological importance that are unlikely to be subject to drift (Coyne et al. 1997; Gavrilets 2003). Such traits are generally under strong stabilizing selection in an environment, so divergence in these traits is unlikely without environmental change (Charlesworth et al. 1982; Coyne et al. 1997; Gavrilets 2003, 2004; Wiens and Graham 2005). Within C. ornatus we found that $\mathrm{N}$ differed in body shape, $\mathrm{H}$ differed in being of substantially smaller body size, and all three lineages differed significantly in terms of mating call. Phenotypic divergence is particularly pronounced for $\mathrm{H}$ and $\mathrm{N}$ (figure 4). We therefore believe that this suggests divergent selection across refugia, particularly those peripheral to the large central refuge. Ultimately, however, we cannot rule out the effects of drift, particularly given the deep divergences (i.e., extended periods of isolation) between the major lineages and the evidently small population sizes in the smaller refugia.

\section{Do the Major Lineages Represent Species?}

To assess the potential for reproductive isolation among C. ornatus lineages, we consider three lines of evidence: call divergence, genetic divergence, and preliminary analysis of secondary contact between two of the lineages $(\mathrm{N}$ vs. C). Calls of the three major lineages of C. ornatus differ significantly in key traits for mate choice and species recognition in frogs (Gerhardt and Huber 2002), suggesting strong potential among the lineages for premating isolation. Sequence divergence among lineages for both mtDNA and nuclear genes is comparable to that among sister species of Cophixalus (Hoskin 2004) and is sufficient to suggest the potential for at least partial postmating isolation (Sasa et al. 1998; Coyne and Orr 2004), as has been found between phylogeographic lineages in other AWT species (Phillips et al. 2004; Hoskin et al. 2005). With respect to the extent of admixture at contact zones, the parapatric boundary between $\mathrm{N}$ and $\mathrm{C}$ is abrupt $(<1 \mathrm{~km})$, with evidence of admixture in just one individual within the densely sampled Mount Bartle Frere transect (fig. 3). By comparison, the $\mathrm{C}$ subgroups show considerable admixture at some sites ( $\mathrm{L}$ vs. BF or S) or more widespread introgression (BF vs. S; fig. 3). These multiple lines of evidence support the recognition of the three major lin- eages $(\mathrm{H}, \mathrm{N}$, and $\mathrm{C})$ as separate species, and these will be described elsewhere.

\section{Future Directions}

This study shows divergence in key morphology and call traits among lineages, which suggests divergent selection across environmentally different refugia. However, on the basis of the data here, it is not possible to resolve the sources of selection or completely discount drift. Hypotheses can be generated, for example, that the smaller size of $\mathrm{H}$ frogs reflects habitat differences. The $\mathrm{H}$ lineage is unique in that it occupies extensive areas of montane heath, a habitat that dominates the uplands of Hinchinbrook Island but is very limited elsewhere in the species range. The shift to heath on Hinchinbrook Island may have caused selection on body size due to differences in physical structure, microenvironment, or community composition compared with rainforest. There are a number of ways in which the origins of phenotypic divergence may be further tested in this and other systems. First, the functionality of divergent traits can be tested against environmental differences (here associated with predicted refugial areas), an approach used to test for adaptation to historic and current environments (e.g., for lizards, see Losos 2009; Collar et al. 2010). Second, the array of pairwise contacts between $\mathrm{N}$ and $\mathrm{C}$ and all three subgroups of $\mathrm{C}$ around Mount Bartle Frere in the central AWT (fig. $3 A$ ) present an ideal setting to test for ecological and mating divergence and the importance of character displacement and reinforcement in completing speciation.

In C. ornatus, phenotypic divergence is particularly apparent for the two peripheral lineages. Similarly, in the north Queensland Cophixalus radiation more broadly, rainforest species are morphologically very similar whereas the few species occupying ecologically distinct, peripheral habitats differ obviously in body size (Hoskin 2004; C. J. Hoskin, unpublished data). This directs attention to the phenotypic analysis of currently or historically isolated peripheral populations. Phenotypic divergence (and hence speciation) may be particularly expected in refugia that are peripheral to core refugial areas because these areas are more likely to have been ecologically marginal or even atypical habitat compared with core areas (Gankin and Major 1964; Endler 1977; Lawton 1993), therefore presenting greater opportunity for divergent selection (Lesica and Allendorf 1995). Such analyses may be particularly profitable on generalist species within a broad habitat type (e.g., rainforest) because they are more likely than specialists to persist in marginal refugia and to have locally adapted phenotypic variation that could be subdivided across isolates. 


\section{Acknowledgments}

We thank K. McDonald and J. Milton for assistance durin the fieldwork and J. Austin and G. Dolman for assistance in the lab. We thank M. Blows and S. P. Wright for assistance with multivariate statistical analyses. For com- $\rightarrow$ menting on an early draft, we thank D. Buckley, A. Carnaval, M. Fujita, R. Pereira, and S. Singhal. For constructive comments that greatly improved the manuscript, we thank N. Barton, L. Knowles, and anonymou: $\rightarrow$ reviewers. This research was supported by grants from the National Science Foundation (to C.M.), the Australian Research Council (to C.J.H.), and the Cooperative Research Centre for Tropical Rainforest Ecology and Management (to C.J.H.), as well as support from the University of Queensland, the Australian National University, James Cook University, the Wet Tropics Management Authority, and Australian Geographic. All procedures were conductec $\rightarrow$ in accordance with Queensland Environmental Protection Agency permits and the University of Queensland animal ethics guidelines.

\section{Literature Cited}

$\rightarrow$ Aljanabi, S. M., and I. Martinez. 1997. Universal and rapid saltextraction of high quality genomic DNA for PCR-based techniques. Nucleic Acids Research 25:4692.

$\rightarrow$ Avise, J. C., and D. Walker. 1998. Pleistocene phylogeographic effects on avian populations and the speciation process. Proceedings of the Royal Society B: Biological Sciences 265:457-463.

$\rightarrow$ Bardeleben, C., M. M. Gray, and C. J. Hoskin. 2006. Isolation or polymorphic tetranucleotide microsatellite markers for the ornate nursery-frog Cophixalus ornatus. Molecular Ecology Notes 6:888890.

$\rightarrow$ Bell, K. L., C. Moritz, A. Moussalli, and D. K. Yeates. 2007. Comparative phylogeography and speciation of dung beetles from the Australian Wet Tropics rainforest. Molecular Ecology 16:49844998.

Bell, R. C., J. L. Parra, M. Tonione, C. J. Hoskin, J. B. MacKenzie, S. E. Williams, and C. Moritz. 2010. Patterns of persistence and isolation indicate resilience to climate change in montane rainforest lizards. Molecular Ecology 19:2531-2544.

$\rightarrow$ Benjamini, Y., and Y. Hochberg. 1995. Controlling the false discovery rate: a practical and powerful approach to multiple testing. Journal of the Royal Statistical Society B: Statistical Methodology 57:289300 .

$\rightarrow$ Bickford, D., D. J. Lohman, N. S. Sodhi, P. K. L. Ng, R. Meier, K. Winker, K. K. Ingram, and I. Das. 2006. Cryptic species as a window on diversity and conservation. Trends in Ecology \& Evolution 22:148-155.

$\rightarrow$ Bond, J. E., and A. K. Stockman. 2008. An integrative method for delimiting cohesion species: finding the population-specific inter face in a group of Californian trapdoor spiders with extreme genetic divergence and geographic structuring. Systematic Biology 57:628-646.

$\rightarrow$ Boyer, S. L., J. M. Baker, and G. Giribet. 2007. Deep genetic diver $\rightarrow$ gences in Aoraki denticulata (Arachnida, Opiliones, Cypho- phthalmi): a widespread "mite harvestman" defies DNA taxonomy. Molecular Ecology 16:4999-5016.

Carnaval, A. C., M. J. Hickerson, C. F. B. Haddad, M. T. Rodrigues, and C. Moritz. 2009. Stability predicts genetic diversity in the Brazilian Atlantic forest hotspot. Science 323:785-789.

$\rightarrow$ Carstens, B. C., and L. L. Knowles. 2007. Shifting distributions and speciation: genomic resolution of species divergence during rapid climate change. Molecular Ecology 16:619-627.

Charlesworth, B., R. Lande, and M. Slatkin. 1982. A neo-Darwinian commentary on macroevolution. Evolution 36:474-498.

Collar, D. C., J. A. Schulte II, B. C. O'Meara, and J. B. Losos. 2010. Habitat use affects morphological diversification in dragon lizards. Journal of Evolutionary Biology 23:1033-1049.

Coope, G. R. 2004. Several million years of stability among insect species because of, or in spite of, Ice Age instability? Philosophical Transactions of the Royal Society B: Biological Sciences 359:209214.

Coyne, J. A., and H. A. Orr. 2004. Speciation. Sinauer, Sunderland, MA.

Coyne, J. A., N. H. Barton, and M. Turelli. 1997. Perspective: a critique of Sewall Wright's shifting balance theory of evolution. Evolution 51:643-671.

$\rightarrow$ Drummond, A. J., and A. Rambaut. 2007. BEAST: Bayesian evolutionary analysis by sampling trees. BMC Evolutionary Biology 7: 214.

$\rightarrow$ Drummond, A. J., A. Rambaut, B. Shapiro, and O. G. Pybus. 2005. Bayesian coalescent inference of past population dynamics from molecular sequences. Molecular Biology and Evolution 22:11851192.

Endler, J. A. 1977. Geographic variation, speciation and clines. Princeton University Press, Princeton, NJ.

. 1986. Natural selection in the wild. Princeton University Press, Princeton, NJ.

$\rightarrow$ Evanno, G., S. Regnaut, and J. Goudet. 2005. Detecting the number of clusters of individuals using the software STRUCTURE: a simulation study. Molecular Ecology 14:2611-2620.

Excoffier, L., G. Laval, and S. Schneider. 2005. Arlequin (version 3.0): an integrated software package for population genetics data analysis. Evolutionary Bioinformatics Online 1:47-50.

Felton, A., R. A. Alford, A. M. Felton, and L. Schwarzkopf. 2006. Multiple mate choice criteria and the importance of age for male mating success in the microhylid frog, Cophixalus ornatus. Behavioral Ecology and Sociobiology 59:786-795.

$\rightarrow$ Futuyma, D. J. 2010. Evolutionary constraint and ecological consequences. Evolution 64:1865-1884.

Gankin, R., and J. Major. 1964. Arctostaphylos myrtifolia, its biology and relationship to the problem of endemism. Ecology 45:793808.

$\rightarrow$ Gavrilets, S. 2003. Perspective: models of speciation: what have we learned in 40 years? Evolution 57:2197-2215.

2004. Fitness landscapes and the origin of species. Princeton University Press, Princeton, NJ.

Gerhardt, H. C., and F. Huber. 2002. Acoustic communication in insects and anurans. University of Chicago Press, Chicago.

Graham, C. H., C. Moritz, and S. E. Williams. 2006. Habitat history improves prediction of biodiversity in rainforest fauna. Proceedings of the National Academy of Sciences of the USA 103:632636.

Graham, R. W., E. L. Lundelius Jr., M. A. Graham, E. K. Schroeder, R. S. Toomey III, E. Anderson, A. D. Barnosky, et al. 1996. Spatial 
response of mammals to Late Quaternary environmental fluctu ations. Science 272:1601-1606.

Greenwood, D. R., and D. C. Christophel. 2005. The origins and Tertiary history of Australian "tropical" rainforests. Pages 374-400 in E. Bermingham, C. W. Dick, and C. Moritz, eds. Tropical rainforests: past, present, and future. University of Chicago Press, Chicago.

$\rightarrow$ Grinnell, J. 1917. Field tests of theories concerning distributional control. American Naturalist 51:115-128.

$\rightarrow$ Haffer, J. 1969. Speciation in Amazonian forest birds. Science 165: 131-137.

$\rightarrow-1997$. Alternative models of vertebrate speciation in Amazonia: an overview. Biodiversity and Conservation 6:451-476.

$\rightarrow$ Hewitt, G. M. 2000. The genetic legacy of the Quaternary ice ages. Nature 405:907-913.

$\rightarrow-$ 2004. Genetic consequences of climatic oscillations in the Quaternary. Philosophical Transactions of the Royal Society B: Biological Sciences 359:183-195.

$\rightarrow$ Hickerson, M. J., B. C. Carstens, J. Cavender-Bares, K. A. Crandall, C. H. Graham, J. B. Johnson, L. Rissler, P. F. Victoriano, and A D. Yoder. 2010. Phylogeography's past, present, and future: 10 years after Avise, 2000. Molecular Phylogenetics and Evolution 54:291301.

$\rightarrow$ Hilbert, D. W., A. Graham, and M. S. Hopkins. 2007. Glacial and interglacial refugia within a long-term rainforest refugium: the Wet Tropics bioregion of north-east Queensland, Australia. Palaeogeography, Palaeoclimatology, Palaeoecology 251:104-118.

$\rightarrow$ Hopkins, M. S., J. Ash, A. W. Graham, J. Head, and R. K. Hewett $\rightarrow$ 1993. Charcoal evidence of the spatial extent of the eucalyptus woodland expansions and rainforest contractions in north Queensland during the late Pleistocene. Journal of Biogeography 20:5974.

$\rightarrow$ Hoskin, C. J. 2004. Australian microhylid frogs (Cophixalus and Austrochaperina): phylogeny, taxonomy, calls, distributions and breeding biology. Australian Journal of Zoology 52:237-269.

$\rightarrow-$ 2007. Description, biology and conservation of a new specie of Australian tree frog (Anura: Hylidae: Litoria) and an assessment of the remaining populations of Litoria genimaculata Horst, 1883: systematic and conservation implications of an unusual speciatior $\rightarrow$ event. Biological Journal of the Linnean Society 91:549-563.

$\rightarrow$ Hoskin, C. J., and M. Higgie. 2010. Speciation via species interactions $\rightarrow$ the divergence of mating traits within species. Ecology Letters 13: 409-420.

$\rightarrow$ Hoskin, C. J., M. Higgie, K. R. McDonald, and C. Moritz. 2005. Reinforcement drives rapid allopatric speciation. Nature 437:1353- $\rightarrow$ 1356.

$\rightarrow$ Huelsenbeck, J. P., and F. Ronquist. 2001. MRBAYES: Bayesian inference of phylogenetic trees. Bioinformatics 17:754-755.

$\rightarrow$ Hugall, A., C. Moritz, A. Moussalli, and J. Stanisic. 2002. Reconciling paleodistribution models and comparative phylogeography in thi $\rightarrow$ Wet Tropics rainforest land snail Gnarosophia bellendenkerensis (Brazier 1875). Proceedings of the National Academy of Sciences of the USA 99:6112-6117.

$\rightarrow$ Jackson, S. T., and J. T. Overpeck. 2000. Responses of plant populations and communities to environmental changes of the late Quaternary. Paleobiology 26:194-220.

Jolliffe, I. T. 2002. Principal components analysis. Springer, New York.

$\rightarrow$ Joseph, L., C. Moritz, and A. Hugall. 1995. Molecular support for vicariance as a source of diversity in rainforest. Proceedings of the Royal Society B: Biological Sciences 260:177-182.
Kershaw, A. P., and H. A. Nix. 1988. Quantitative palaeoclimatic estimates from pollen core data using bioclimatic profiles of extant taxa. Journal of Biogeography 15:589-602.

Kershaw, A. P., P. T. Moss, and R. Wild. 2005. Patterns and causes of vegetation change in the Australian Wet Tropics region over the last 10 million years. Pages 374-400 in E. Bermingham, C. W. Dick, and C. Moritz, eds. Tropical rainforests: past, present, and future. University of Chicago Press, Chicago.

$\rightarrow$ Kirschel, A. N. G., D. T. Blumstein, R. E. Cohen, W. Buermann, T. B. Smith, and H. Slabbekoorn. 2009. Birdsong tuned to the environment: green hylia song varies with elevation, tree cover, and noise. Behavioral Ecology 20:1089-1095.

Klicka, J., and R. M. Zink. 1997. The importance of recent ice ages in speciation: a failed paradigm. Science 277:1666-1669.

$\rightarrow$ Knowles, L. L. 2000. Tests of Pleistocene speciation in montane grasshoppers from the sky islands of western North America (genus Melanoplus). Evolution 54:1337-1348.

$\rightarrow$ - 2009. Statistical phylogeography. Annual Review of Ecology, Evolution, and Systematics 40:593-612.

Knowles, L. L., B. C. Carstens, and M. L. Keat. 2007. Coupling genetic and ecological-niche models to examine how past population distributions contribute to divergence. Current Biology 17:940-946.

Köhler, F., and R. Günther. 2008. The radiation of microhylid frogs (Amphibia: Anura) on New Guinea: a mitochondrial phylogeny reveals parallel evolution of morphological and life history traits and disproves the current morphology-based classification. Molecular Phylogenetics and Evolution 47:353-365.

Kozak, K. H., and J. J. Wiens. 2006. Does niche conservatism promote speciation? a case study in North American salamanders. Evolution 60:2604-2621.

$\rightarrow$ Kozak, K. H., D. W. Weisrock, and A. Larson. 2006. Rapid lineage accumulation in a non-adaptive radiation: phylogenetic analysis of diversification rates in eastern North American woodland salamanders (Plethodontidae: Plethodon). Proceedings of the Royal Society B: Biological Sciences 273:539-546.

Kuhner, M. K. 2006. LAMARC 2.0: maximum likelihood and Bayesian estimation of population parameters. Bioinformatics 22:768770 .

Lawton, J. H. 1993. Range, population abundance and conservation. Trends in Ecology \& Evolution 8:409-413.

Lesica, P., and F. W. Allendorf. 1995. When are peripheral populations valuable for conservation? Conservation Biology 9:753-760.

Losos, J. B. 2009. Lizards in an evolutionary tree: ecology and adaptive radiation of anoles. University of California Press, Berkeley.

Lynch, M. 1990. The rate of morphological evolution in mammals from the standpoint of the neutral expectation. American Naturalist 136:727-741.

$\rightarrow$ McPeek, M. A. 1996. Linking local species interactions to rates of speciation in communities. Ecology 77:1355-1366.

McPeek, M. A., and S. Gavrilets. 2006. The evolution of female mating preferences: differentiation from species with promiscuous males can promote speciation. Evolution 60:1967-1980.

$\rightarrow$ Meegaskumbura, M., F. Bossuyt, R. Pethiyagoda, K. ManamendraArachchi, M. Bahir, M. C. Milinkovitch, and C. J. Schneider. 2002. Sri Lanka: an amphibian hot spot. Science 298:379.

$\rightarrow$ Moritz, C., J. L. Patton, C. J. Schneider, and T. B. Smith. 2000. Diversification of rainforest faunas: an integrated molecular approach. Annual Review of Ecology and Systematics 31:533-563.

Moritz, C., J. L. Patton, C. J. Conroy, J. L. Parra, G. C. White, and S. R. Beissinger. 2008. Impact of a century of climate change on 
small-mammal communities in Yosemite National Park, USA. Sci $\rightarrow$ Ryan, M. J., and W. Wilczynski. 1991. Evolution of intraspecific varence 10:261-264.

$\rightarrow$ Moritz, C., C. J. Hoskin, J. B. MacKenzie, B. L. Phillips, M. Tonione, N. Silva, J. VanDerWal, S. E. Williams, and C. H. Graham. 2009. Identification and dynamics of a cryptic suture zone in tropical rainforest. Proceedings of the Royal Society B: Biological Science $\rightarrow$ 276:1235-1244. iation in the advertisement call of a cricket frog (Acris crepitans, Hylidae). Biological Journal of the Linnean Society 44:249-271.

SAS Institute. 2010. SAS/STAT 9.22 user's guide. SAS Institute, Cary, NC.

Sasa, M. M., P. T. Chippindale, and N. A. Johnson. 1998. Patterns of postzygotic isolation in frogs. Evolution 52:1811-1820.

$\rightarrow$ Moussalli, A., C. Moritz, S. E. Williams, and A. C. Carnaval. $2009 \rightarrow$ Schluter, D. 2001. Ecology and the origin of species. Trends in Ecology Variable responses of skinks to a common history of rainforest fluctuation: concordance between phylogeography and palaeo-dis $\rightarrow$ tribution models. Molecular Ecology 18:483-499.

Nix, H. A. 1991. Biogeography: patterns and process. Pages 11-39 in H. A. Nix and M. Switzer, eds. Rainforest animals: atlas o $\rightarrow$ vertebrates endemic to Australia's Wet Tropics. Australian National Parks and Wildlife Service, Canberra.

$\rightarrow$ Nosil, P., and S. M. Flaxman. 2011. Conditions for mutation-order speciation. Proceedings of the Royal Society B: Biological Science 278:399-407.

Nott, J. 2005. The origin and evolution of Australia's eastern highlands. Pages 374-400 in E. Bermingham, C. W. Dick, and C. Moritz, eds. Tropical rainforests: past, present, and future. Universitof Chicago Press, Chicago.

$\rightarrow$ Parmesan, C. 2006. Ecological and evolutionary responses to recent climate change. Annual Review of Ecology, Evolution, and Sys tematics 37:637-669.

$\rightarrow$ Petit, R. J., I. Aguinagalde, J.-L. de Beaulieu, C. Bittkau, S. Brewer, R. Cheddadi, R. Ennos, et al. 2003. Glacial refugia: hotspots bu+ not melting pots of genetic diversity. Science 300:1563-1565.

$\rightarrow$ Phillips, B. L., S. J. E. Baird, and C. Moritz. 2004. When vicars meet: a narrow contact zone between morphologically cryptic phylo geographic lineages of the rainforest skink, Carlia rubrigularis. Evolution 58:1536-1549.

$\rightarrow$ Phillips, S. J., R. P. Anderson, and R. E. Schapire. 2006. Maximum entropy modeling of species geographic distributions. Ecological Modelling 190:231-259.

$\rightarrow$ Posada, D., and K. A. Crandall 1998. Modeltest: testing the model of DNA substitution. Bioinformatics 14:817-818.

Pritchard, J. K., M. Stephens, and P. Donnelly. 2000. Inference of population structure using multilocus genotype data. Genetics 155 . 945-959.

Rambaut A., and A. J. Drummond. 2007. Tracer, version 1.4. http: //beast.bio.ed.ac.uk/Tracer.

$\rightarrow$ Rice, W. R., and E. E. Hostert. 1993. Laboratory experiments on speciation: what have we learned in 40 years? Evolution $47: 1637-$ 1653.

$\rightarrow$ Richards, C. L., B. C. Carstens, and L. L. Knowles. 2007. Distribution modelling and statistical phylogeography: an integrative framework for generating and testing alternative biogeographical hypotheses. Journal of Biogeography 34:1833-1845. \& Evolution 16:372-380.

Schneider, C. J. S., and C. Moritz. 1999. Refugial isolation and evolution in the Wet Tropics rainforests of Australia. Proceedings of the Royal Society B: Biological Sciences 266:191-196.

Schneider, C. J. S., M. Cunningham, and C. Moritz. 1998. Comparative phylogeography and the history of endemic vertebrates in the Wet Tropics rainforest of Australia. Molecular Ecology 7:487498 .

Schneider, C. J. S., T. B. Smith, B. Larison, and C. Moritz. 1999. A test of alternative models of diversification in tropical rainforests: ecological gradients vs. refugia. Proceedings of the National Academy of Sciences of the USA 96:13869-13873.

Smith, T. B., R. K. Wayne, D. J. Girman, and M. W. Bruford. 1997. A role for ecotones in generating rainforest biodiversity. Science 276:1855-1857.

$\rightarrow$ Soberon, J., and M. Nakamura. 2009. Niches and distributional areas: concepts, methods and assumptions. Proceedings of the National Academy of Sciences of the USA 106:19644-19650.

Stamatakis, A., P. Hoover, and J. Rougemont. 2008. A rapid bootstrap algorithm for the RAxML web-servers. Systematic Biology 75:758771.

$\rightarrow$ Starrett, J., and M. Hedin. 2007. Multilocus genealogies reveal multiple cryptic species and biogeographical complexity in the California turret spider Antrodiaetus riversi (Mygalomorphae, Antrodiaetidae). Molecular Ecology 16:583-604.

Stephens, M., N. J. Smith, and P. Donnelly. 2001. A new statistical method for haplotype reconstruction from population data. American Journal of Human Genetics 68:978-989.

Swofford, D. L. 2003. PAUP ${ }^{*}$ : phylogenetic analysis using parsimony ( ${ }^{*}$ and other methods), version 4. Sinauer, Sunderland, MA.

$\rightarrow$ Tingley, M. W., W. B. Monahan, S. R. Beissinger, and C. Moritz. 2009. Birds track their Grinnellian niche through a century of climate change. Proceedings of the National Academy of Sciences of the USA 106:19637-19643.

$\rightarrow$ Tobias, J. A., J. Aben, R. T. Brumfield, E. P. Derryberry, W. Halfwerk, H. Slabbekoorn, and N. Seddon. 2010. Song divergence by sensory drive in Amazonian birds. Evolution 64:2820-2838.

$\rightarrow$ Turgeon, J., R. Stoks, R. A. Thum, J. M. Brown, and M. A. McPeek. 2005. Simultaneous Quaternary radiations of three damselfly clades across the Holarctic. American Naturalist 165:E78-E107.

$\rightarrow$ Roberts, J. L., J. L. Brown, R. von May, W. Arizabal, R. Schulte, anc K. Summers. 2006. Genetic divergence and speciation in lowland and montane Peruvian poison frogs. Molecular Phylogenetics and Evolution 41:149-164.

$\rightarrow$ Roelants, K., D. Gower, M. Wilkinson, S. Loader, S. D. Biju, K. $\rightarrow$ Guillaume, L. Moriau, and F. Bossuyt. 2007. Global patterns of diversification in the history of modern amphibians. Proceedings of the National Academy of Sciences of the USA 104:887-892.

VanDerWal, J., L. P. Shoo, and S. E. Williams. 2009. New approaches to understanding late Quaternary climate fluctuations and refugial dynamics in Australian wet tropical rain forests. Journal of Biogeography 36:291-301.

Vieites, D. R., K. C. Wollenberg, F. Andreone, J. Köhler, F. Glaw, and M. Vences. 2009. Vast underestimation of Madagascar's biodiversity evidenced by an integrative amphibian inventory. Proceedings of the National Academy of Sciences of the USA 106:8267-8272.

$\rightarrow$ Rull, V. 2008. Speciation timing and Neotropical biodiversity: th Tertiary-Quaternary debate in the light of molecular phylogenetic evidence. Molecular Ecology 17:2722-2729.

Walker, M. J., A. K. Stockman, P. E. Marek, and J. E. Bond. 2009. Pleistocene glacial refugia across the Appalachian Mountains and coastal plain in the millipede genus Narceus: evidence from pop- 
ulation genetic, phylogeographic, and paleoclimatic data. BMC Evolutionary Biology 9:25.

Webb, L., and J. Tracey. 1981. Australian rainforests: pattern and change. Pages 607-694 in J. A. Keast, ed. Ecological biogeography of Australia. Junk, The Hague.

$\rightarrow$ Weinstock, J., E. Willerslev, A. Sher, W. Tong, S. Y. W. Ho, D. Rubinstein, J. Storer, et al. 2005. Evolution, systematics, and phylo geography of Pleistocene horses in the New World: a molecular perspective. PLoS Biology 3:e241.

Wells, K. D. 2007. The ecology and behavior of amphibians. University of Chicago Press, Chicago.

$\rightarrow$ Wiens, J. J., and C. H. Graham. 2005. Niche conservatism: integrating evolution, ecology, and conservation biology. Annual Review of Ecology, Evolution, and Systematics 36:519-539.

$\rightarrow$ Williams, J. W., S. T. Jackson, and J. E. Kutzback. 2007. Projected distributions of novel and disappearing climates by 2100 AD. Proceedings of the National Academy of Sciences of the USA 104: 5738-5742.

$\rightarrow$ Williams, S. E., J. VanDerWal, J. Isaac, L. Shoo, C. Storlie, S. Fox, E. E. Bolitho, C. Moritz, C. J. Hoskin, and Y. Williams. 2010.
Distributions, life-history specialization, and phylogeny of the rainforest vertebrates in the Australian Wet Tropics. Ecology 91: 2493.

Wright, S. P. 1998. Multivariate analysis using the MIXED procedure. Proceedings of the 23rd Annual SAS Users Group International Conference, pp. 1238-1242.

Zink, R. M., and J. B. Slowinski. 1995. Evidence from molecular systematics for decreased avian diversification in the Pleistocene epoch. Proceedings of the National Academy of Sciences of the USA 92:5832-5835.

$\rightarrow$ Zink, R. M., J. Klicka, and B. R. Barber. 2004. The tempo of avian diversification during the Quaternary. Philosophical Transactions of the Royal Society B: Biological Sciences 359:215-220.

Zweifel, R. G. 1985. Australian frogs of the family Microhylidae. Bulletin of the American Museum of Natural History 182:265388.

Associate Editor: Scott J. Steppan Editor: Mark A. McPeek

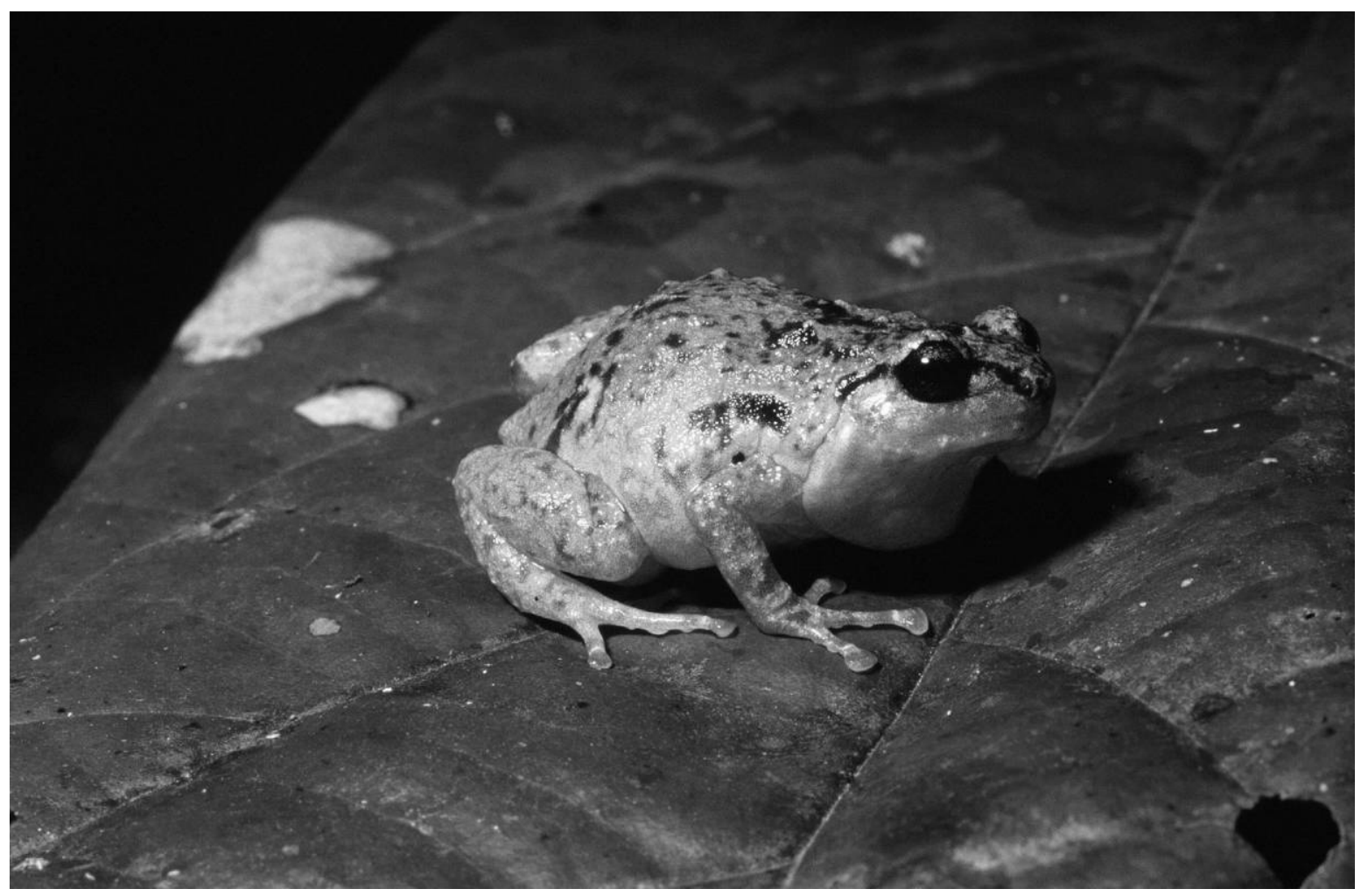

Male ornate nursery frog (Cophixalus ornatus) sitting on a leaf. Photograph by Conrad Hoskin. 